\title{
Safety Assessment of Benzyne Generation from a Silyl Triflate Precursor
}

\author{
Andrew V. Kelleghan ${ }^{\dagger}$, Carl A. Busacca ${ }^{\ddagger}$, Max Sarvestani ${ }^{\ddagger}$ Ivan Volchkov ${ }^{\ddagger}$, \\ Jose M. Medina ${ }^{\dagger}$, and Neil K. Garg ${ }^{\dagger *}$ \\ ${ }^{\dagger}$ Department of Chemistry and Biochemistry, \\ University of California, Los Angeles, California 90095 \\ * Chemical Development, Boehringer Ingelheim Pharmaceuticals, Inc, \\ 900 Ridgebury Road, Ridgefield, Connecticut 06877
}

\section{Supporting Information - Table of Contents}

Materials and Methods 2

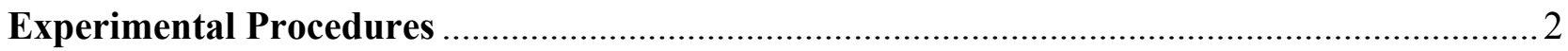

A. Preparation of Reaction Mixtures for ARSST Analysis ....................................... 2

B. Advanced Reactive System Screening Tool (ARSST) Calorimetry Procedure.............. 3

C. Preparation of Samples for Differential Scanning Calorimetry ............................... 4

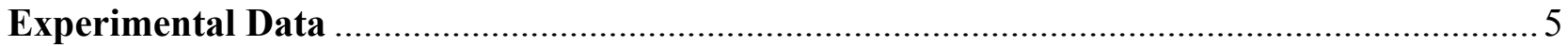

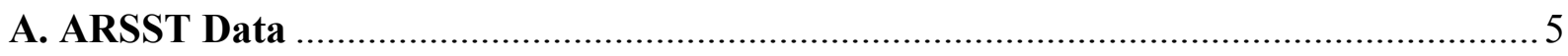

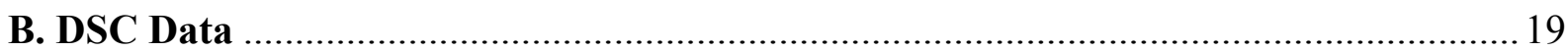

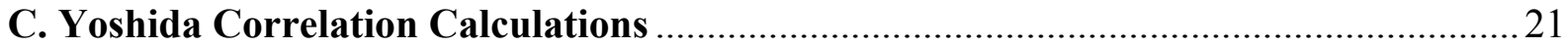

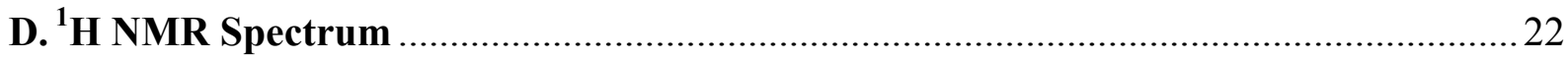

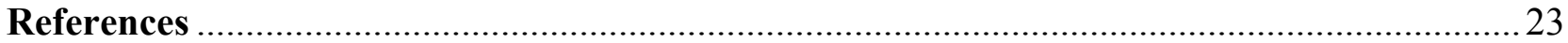


Materials and Methods: 2-(Trimethylsilyl)phenyl trifluoromethanesulfonate, tetrabutylammonium fluoride (TBAF), acetonitrile, CsF, and furan were purchased from Sigma-Aldrich. Adiabatic calorimetry was conducted in an Advanced Reactive System Screening Tool (ARSST) calorimeter manufactured by Fauske and Associates and equipped with a spherical $10 \mathrm{~mL}$ glass test cell, heating jacket, thermocouple, pressure transducer, and a $350 \mathrm{~mL}$ containment vessel. Nitrogen pressure was used to suppress boiling of the sample. All data points shown in the plots are smoothed over five data points. Differential Scanning Calorimetry (DSC) was conducted on a Mettler Toledo DSC 3+ STARe system equipped with an FRS $6+$ sensor. Heating rates were set to $4{ }^{\circ} \mathrm{C} / \mathrm{min}$ and samples were tested in a closed gold-plated crucible. Silicycle Siliaflash P60 (particle size $0.040-0.063 \mathrm{~mm}$ ) was used for flash column chromatography. ${ }^{1} \mathrm{H}-\mathrm{NMR}$ spectra were recorded on Bruker spectrometers (at 500 $\mathrm{MHz})$.

\section{Experimental Procedures}

\section{A. Preparation of Reaction Mixtures for ARSST Analysis:}

Reaction Mixture A (Standard conditions): To a stirred solution of silyl triflate 3 (500 mg, 1.7 mmol, 1.0 equiv) and furan (6) $\left(370 \mu \mathrm{L}, 5.0 \mathrm{mmol}, 3.0\right.$ equiv) in $\mathrm{CH}_{3} \mathrm{CN}(17 \mathrm{~mL}, 0.1 \mathrm{M})$ was added CsF (1.3 g, $8.4 \mathrm{mmol}, 5.0$ equiv) in one portion. The reaction vessel was sealed and placed in an aluminum heating block which was maintained at $60^{\circ} \mathrm{C}$ for $22 \mathrm{~h}$ with continuous stirring.

Reaction Mixture B (No furan added): To a stirred solution of silyl triflate 3 (500 mg, $1.7 \mathrm{mmol}$, 1.0 equiv) in $\mathrm{CH}_{3} \mathrm{CN}(17 \mathrm{~mL}, 0.1 \mathrm{M})$ was added $\mathrm{CsF}(1.3 \mathrm{~g}, 8.4 \mathrm{mmol}, 5.0$ equiv) in one portion. The reaction vessel was sealed and placed in an aluminum heating block which was maintained at $60{ }^{\circ} \mathrm{C}$ for $22 \mathrm{~h}$ with continuous stirring.

Reaction Mixture C (TBAF instead of CsF): To a stirred solution of silyl triflate 3 (500 mg, 1.7 mmol, 1.0 equiv) and furan (6) $\left(370 \mu \mathrm{L}, 5.0 \mathrm{mmol}, 3.0\right.$ equiv) in $\mathrm{CH}_{3} \mathrm{CN}(14 \mathrm{~mL}, 0.1 \mathrm{M})$ was added TBAF (3.4 mL, $3.4 \mathrm{mmol}$, 2 equiv, $1 \mathrm{M}$ in THF) in one portion. The reaction vessel was sealed and 
placed in an aluminum heating block which was maintained at $60{ }^{\circ} \mathrm{C}$ for $22 \mathrm{~h}$ with continuous stirring.

\section{B. Advanced Reactive System Screening Tool (ARSST) Calorimetry Procedure:}

General calorimetry procedure: A $10 \mathrm{~mL}$ test cell, equipped with a teflon-coated, magnetic stir bar, inside the closed containment vessel was purged with $\mathrm{N}_{2}$. A sample of Reaction Mixture A, B, or C (see above) was added to the ARSST test cell by syringe through the instrument's fill tube. The reaction was maintained under 335 bar $\mathrm{N}_{2}$ to suppress solvent boiling, and temperature was gradually increased according to a $\sim 2{ }^{\circ} \mathrm{C} / \mathrm{min}$ ramp polynomial which maintained heating for $85-205 \mathrm{~min}$ from $23{ }^{\circ} \mathrm{C}$ to $130-210{ }^{\circ} \mathrm{C}$. Stirring was maintained throughout the experiment. The mixture was then allowed to cool back to $23{ }^{\circ} \mathrm{C}$ over an additional 30-50 min. Temperature and pressure measurements were collected continuously throughout the duration of the experiment (Figures $3 \& 4$, Figures S1S7).

\footnotetext{
ARSST Calorimetry Experiment for Standard Reaction Conditions: General calorimetry procedure was followed for samples taken from Reaction Mixture A at three time points: $t=0 \mathrm{~h}, \mathrm{t}=3$ $\mathrm{h}, \mathrm{t}=22 \mathrm{~h}$. (See Figures S1-S3)
}

ARSST Calorimetry Experiments without Stirring: General calorimetry procedure was modified by excluding the stir bar from the experiment. Experiments were otherwise conducted according to the general procedure using samples taken from Reaction Mixture A at three time points: $\mathrm{t}=0 \mathrm{~h}, \mathrm{t}=$ 22 h. (See Figures S4-S5)

ARSST Calorimetry Experiments without Furan: General calorimetry procedure was followed for a sample taken from Reaction Mixture B at time $t=0 \mathrm{~h}$. (See Figure S6)

ARSST Calorimetry Experiments with TBAF: General calorimetry procedure was followed for a sample taken from Reaction Mixture $\mathrm{C}$ at time $\mathrm{t}=0 \mathrm{~h}$. (See Figure S7) 


\section{Preparation of Samples for Differential Scanning Calorimetry:}

Preparation of Crude Oxabicycle 7: After $22 \mathrm{~h}$, Reaction Mixture A was cooled to $23{ }^{\circ} \mathrm{C}$, and the heterogeneous mixture was filtered over silica gel, eluting with EtOAc. The filtrate was concentrated under reduced pressure to afford crude product. The crude was suspended in 1:1 EtOAc/hexane (v/v) mixture, and resultant slurry was filtered. The filtrate was concentrated under reduced pressure to afford oxabicycle as a colorless oil, which was used for DSC analysis.

Preparation of Pure Oxabicycle 7: Crude oxabicycle 7 (see above) was purified by column chromatography (19:1 hexanes:EtOAc) to provide pure oxabicycle 7 as a white solid (227 mg, 94\% yield - spectral data consistent with literature values ${ }^{1}$ ) which was used for DSC analysis. 


\section{Experimental Data}

A. ARSST Data

Figure S1a: Time derivative of temperature vs. time plot obtained by ARSST calorimetry of Reaction Mixture A at $\mathrm{t}=0 \mathrm{~h}$.

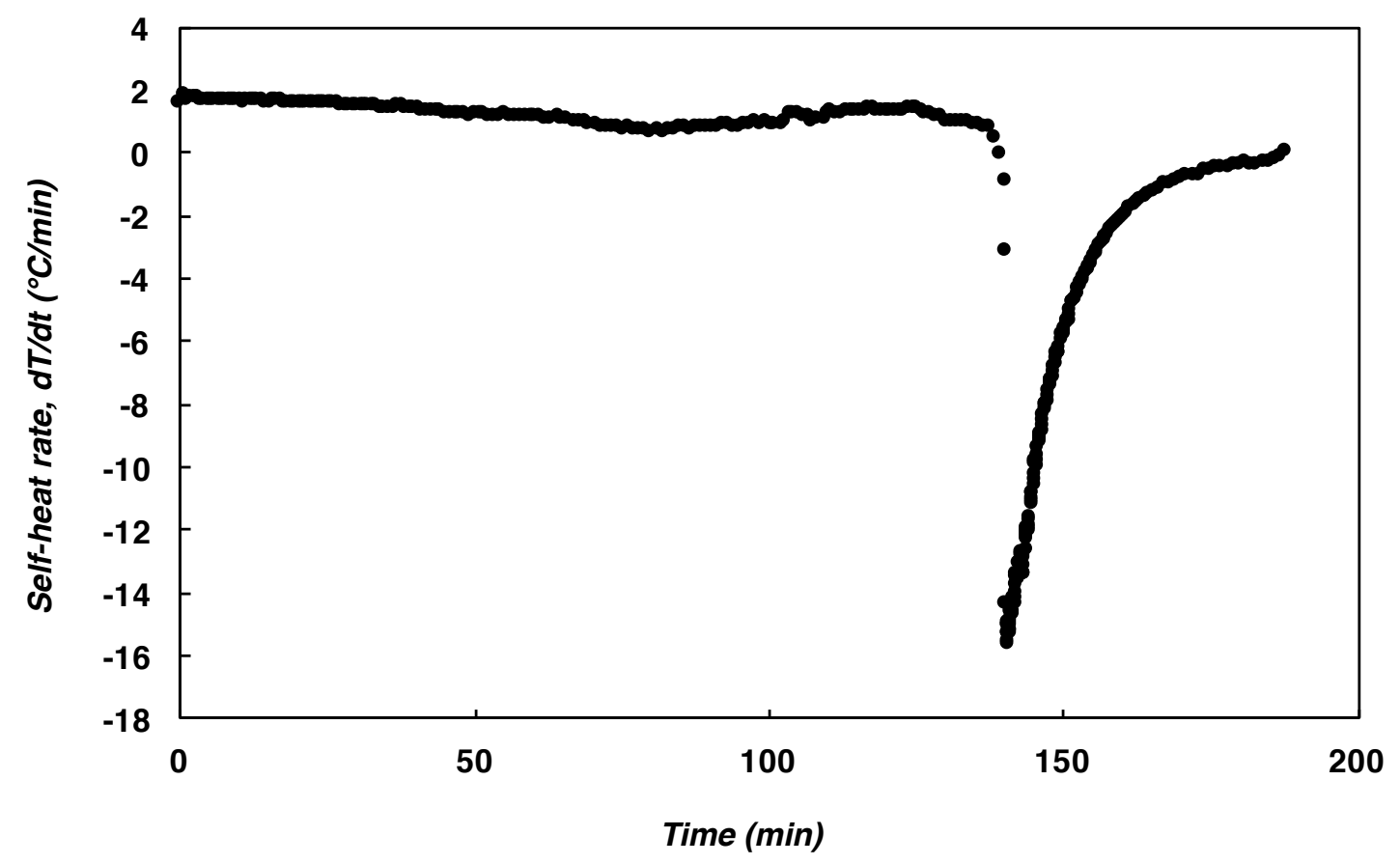

Figure S1b: Time derivative of pressure vs. time plot obtained by ARSST calorimetry of Reaction Mixture $\mathrm{A}$ at $\mathrm{t}=0 \mathrm{~h}$.

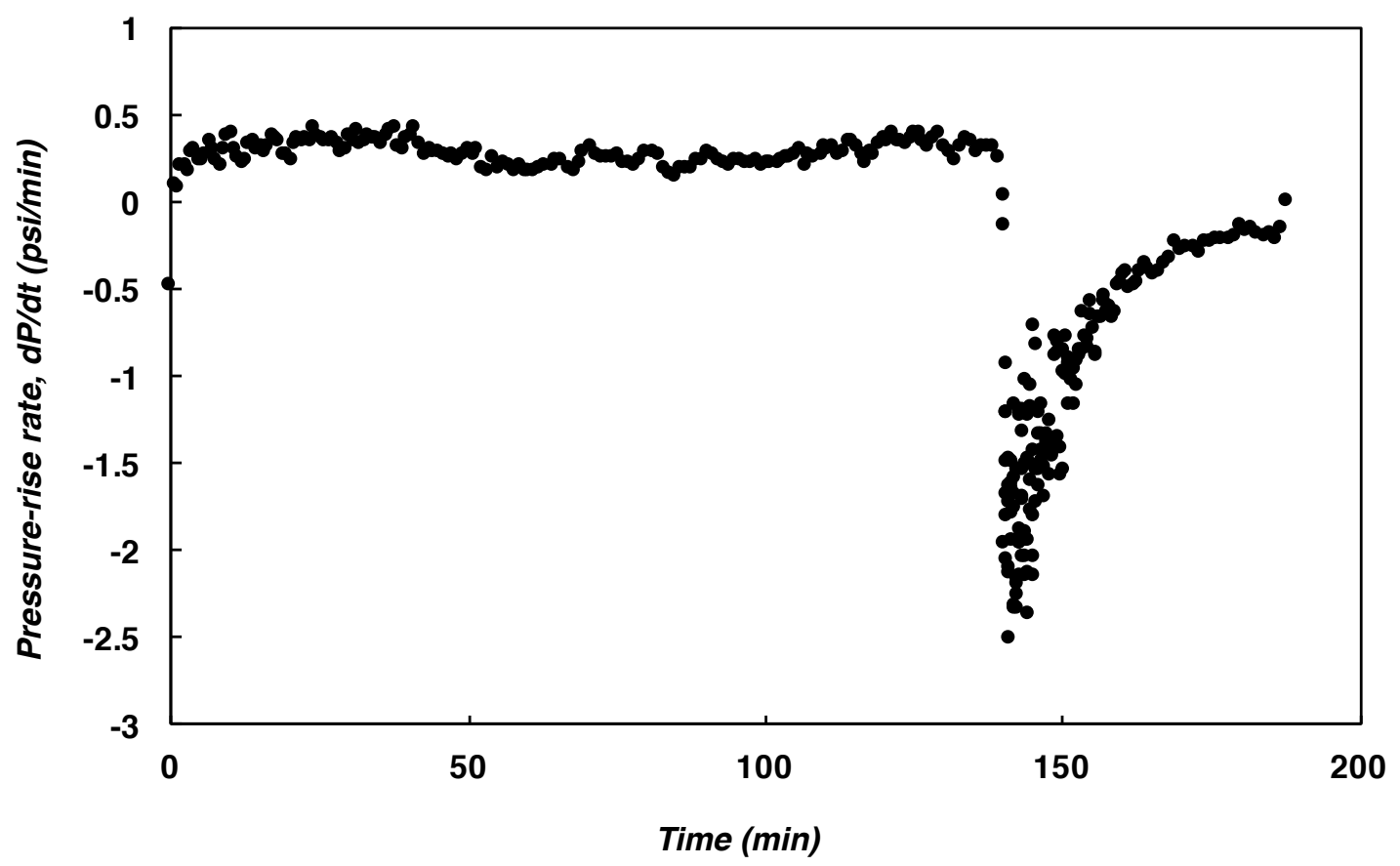


Figure S1c: Temperature vs. time plot obtained by ARSST calorimetry of Reaction Mixture A at $\mathrm{t}=0 \mathrm{~h}$.

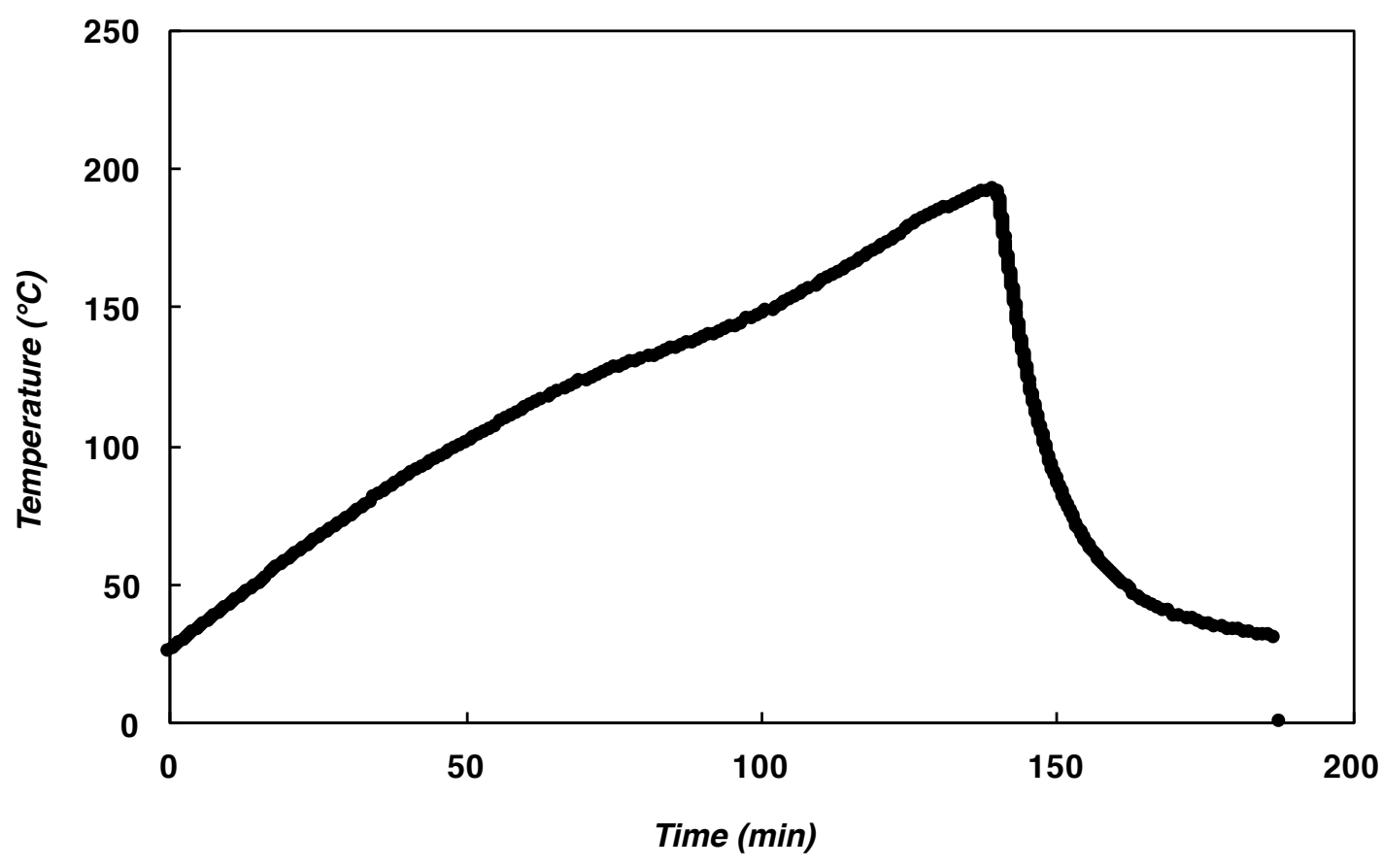

Figure S1d: Pressure vs. time plot obtained by ARSST calorimetry of Reaction Mixture A at $\mathrm{t}=0 \mathrm{~h}$.

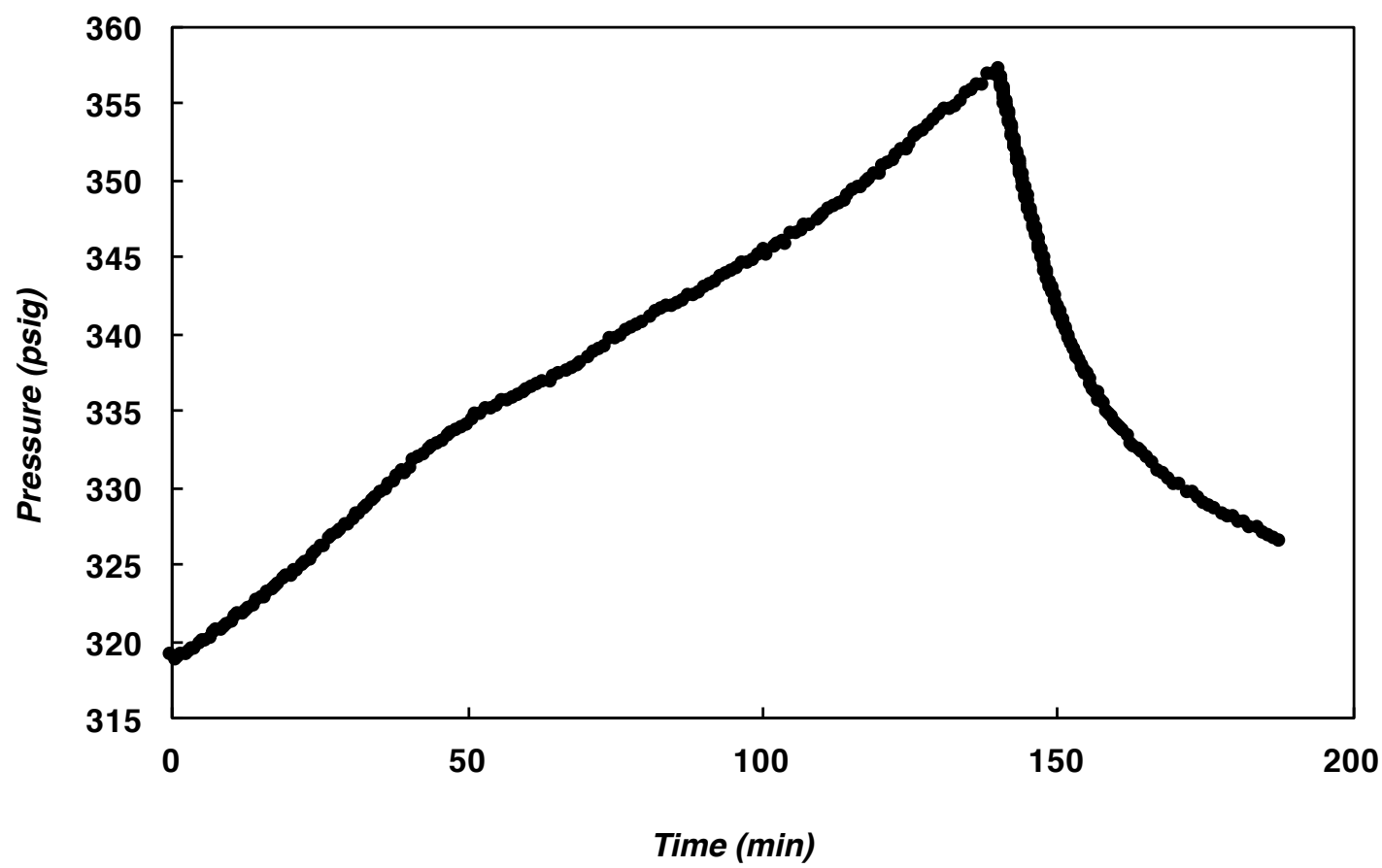


Figure S2a: Time derivative of temperature vs. time plot obtained by ARSST calorimetry of Reaction Mixture A at $\mathrm{t}=3 \mathrm{~h}$.

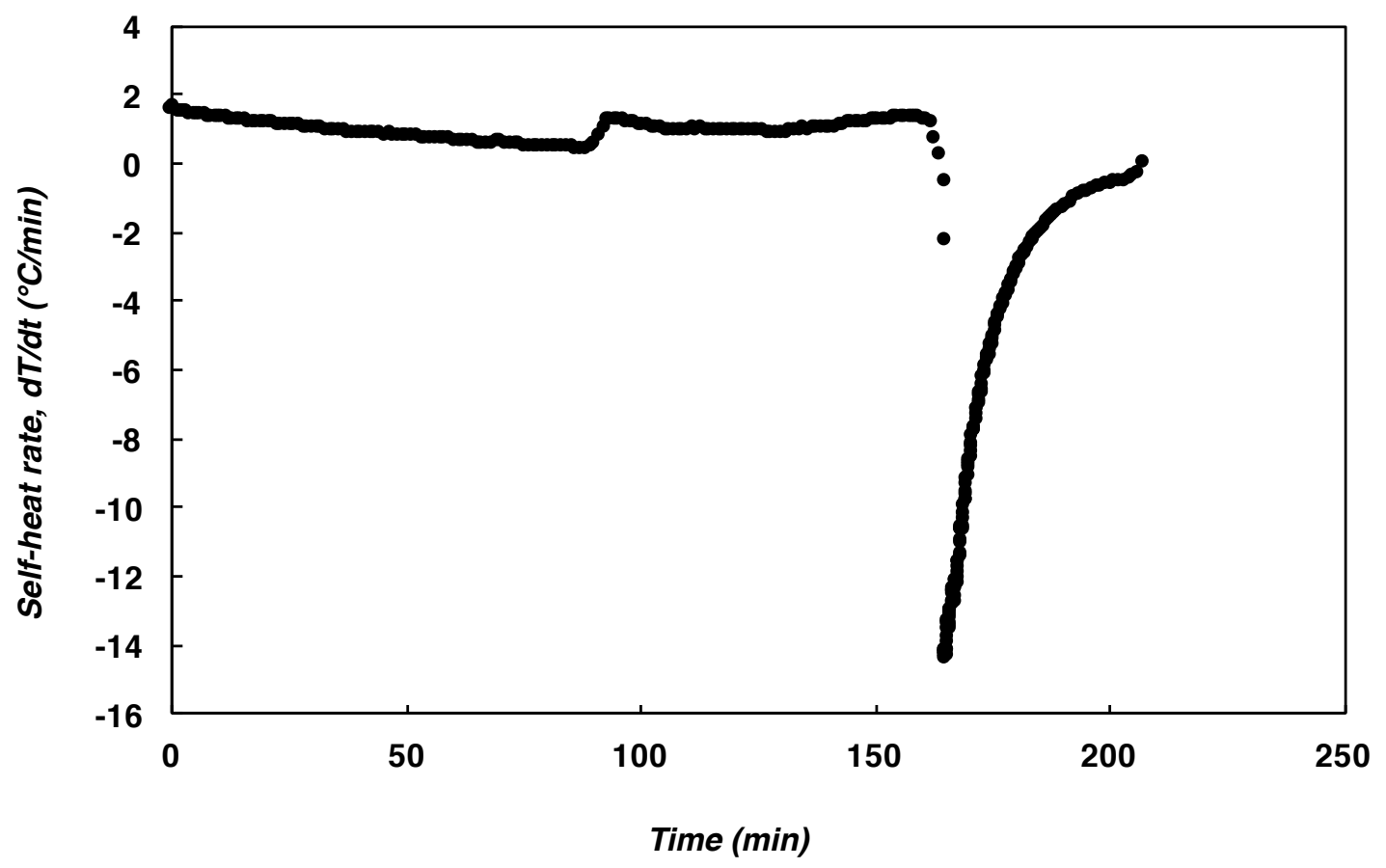

Figure S2b: Time derivative of pressure vs. time plot obtained by ARSST calorimetry of Reaction Mixture A at $\mathrm{t}=3 \mathrm{~h}$.

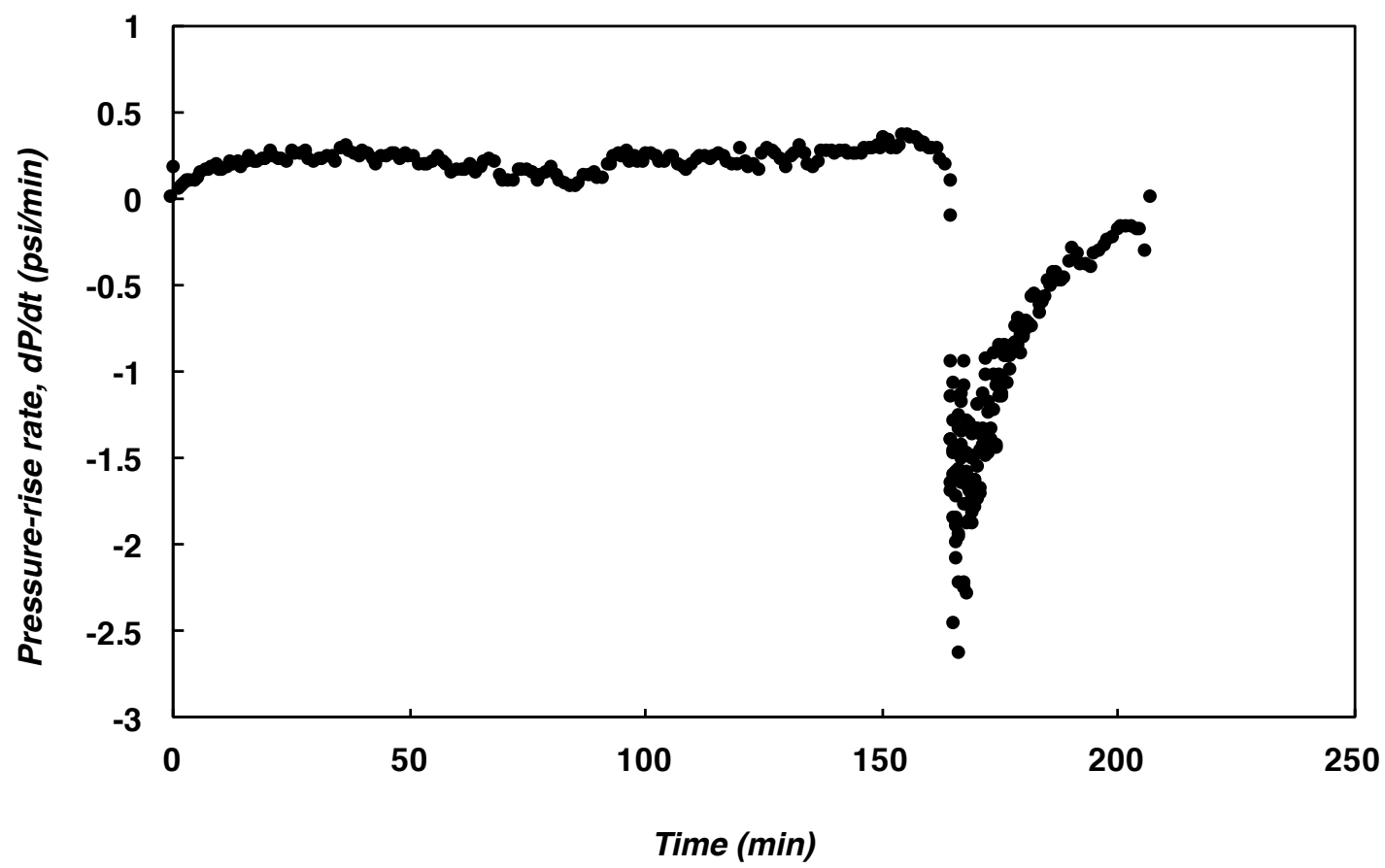


Figure S2c: Temperature vs. time plot obtained by ARSST calorimetry of Reaction Mixture A at $\mathrm{t}=3 \mathrm{~h}$.

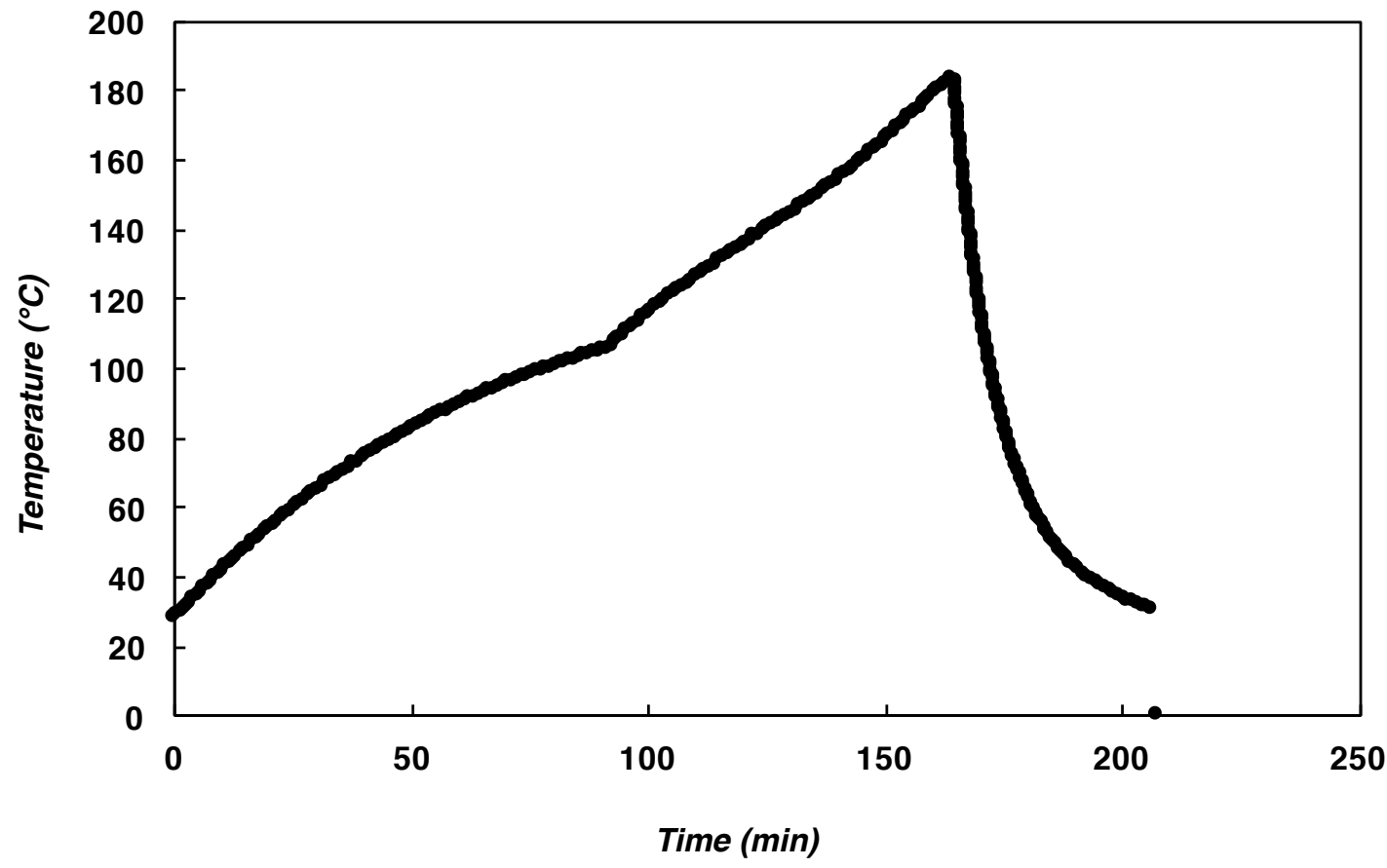

Figure S2d: Pressure vs. time plot obtained by ARSST calorimetry of Reaction Mixture A at $\mathrm{t}=3 \mathrm{~h}$.

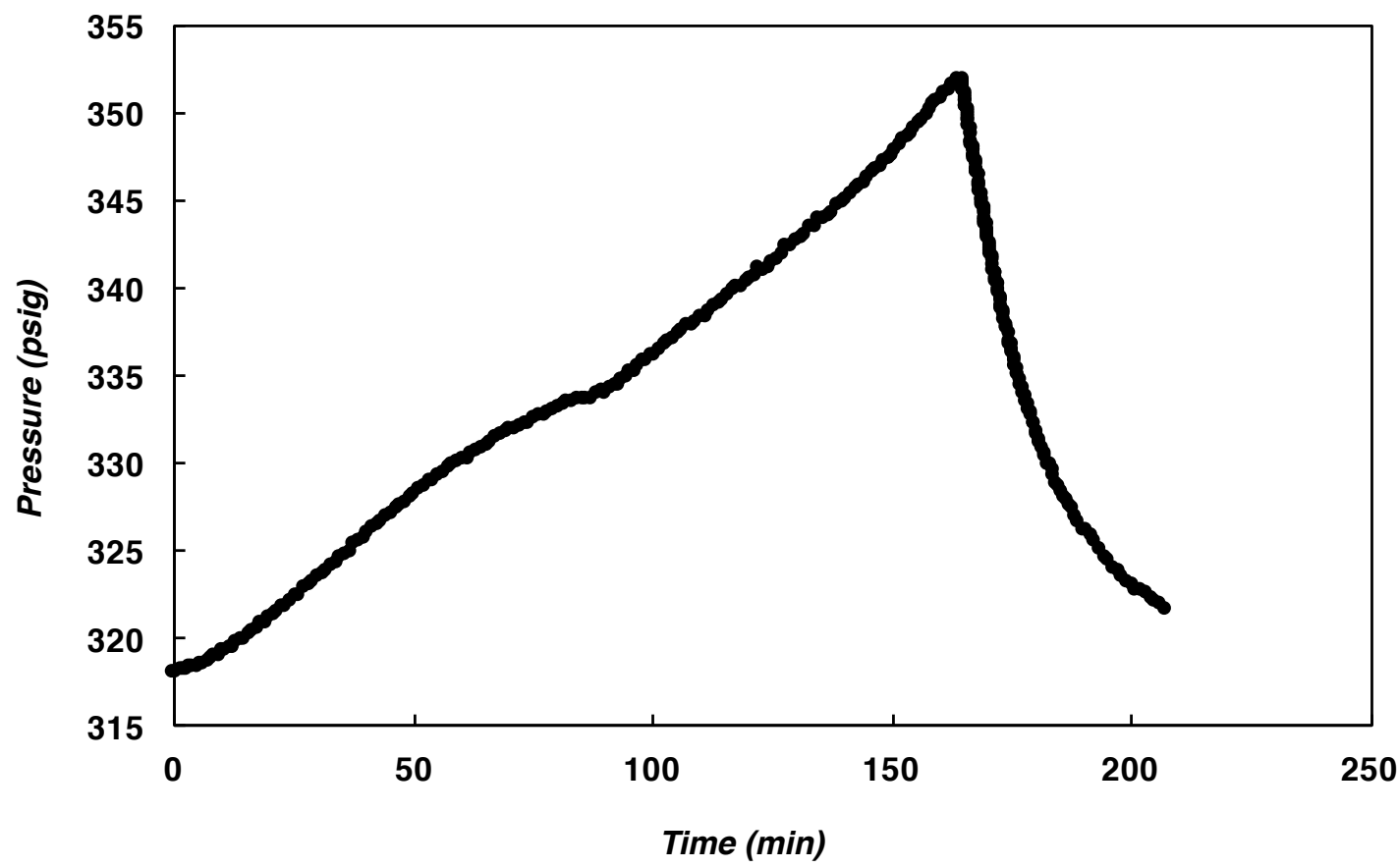


Figure S3a: Time derivative of temperature vs. time plot obtained by ARSST calorimetry of Reaction Mixture A at $t=22 \mathrm{~h}$.

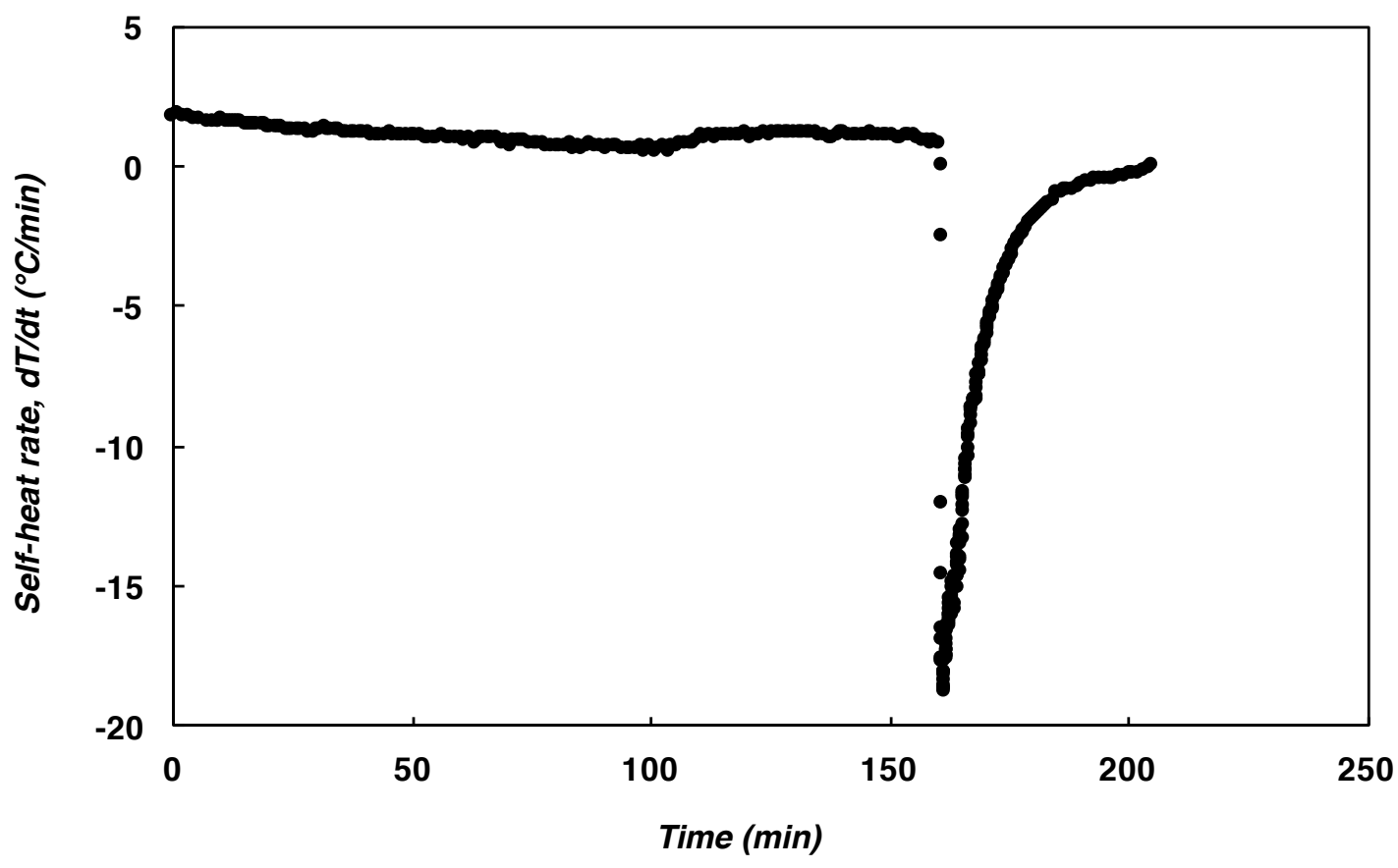

Figure S3b: Time derivative of pressure vs. time plot obtained by ARSST calorimetry of Reaction Mixture A at $\mathrm{t}=22 \mathrm{~h}$.

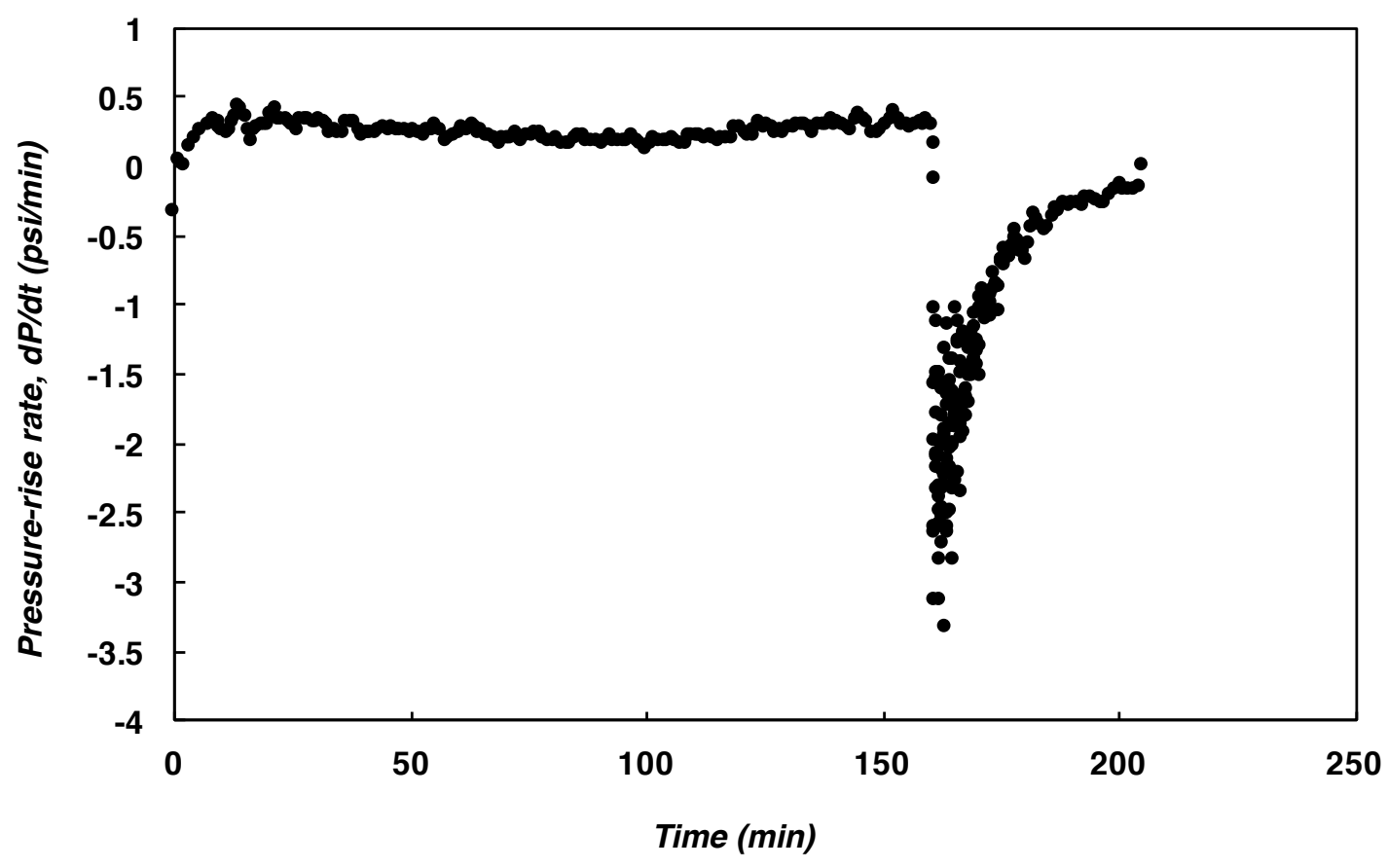


Figure S3c: Temperature vs. time plot obtained by ARSST calorimetry of Reaction Mixture A at $\mathrm{t}=22 \mathrm{~h}$.

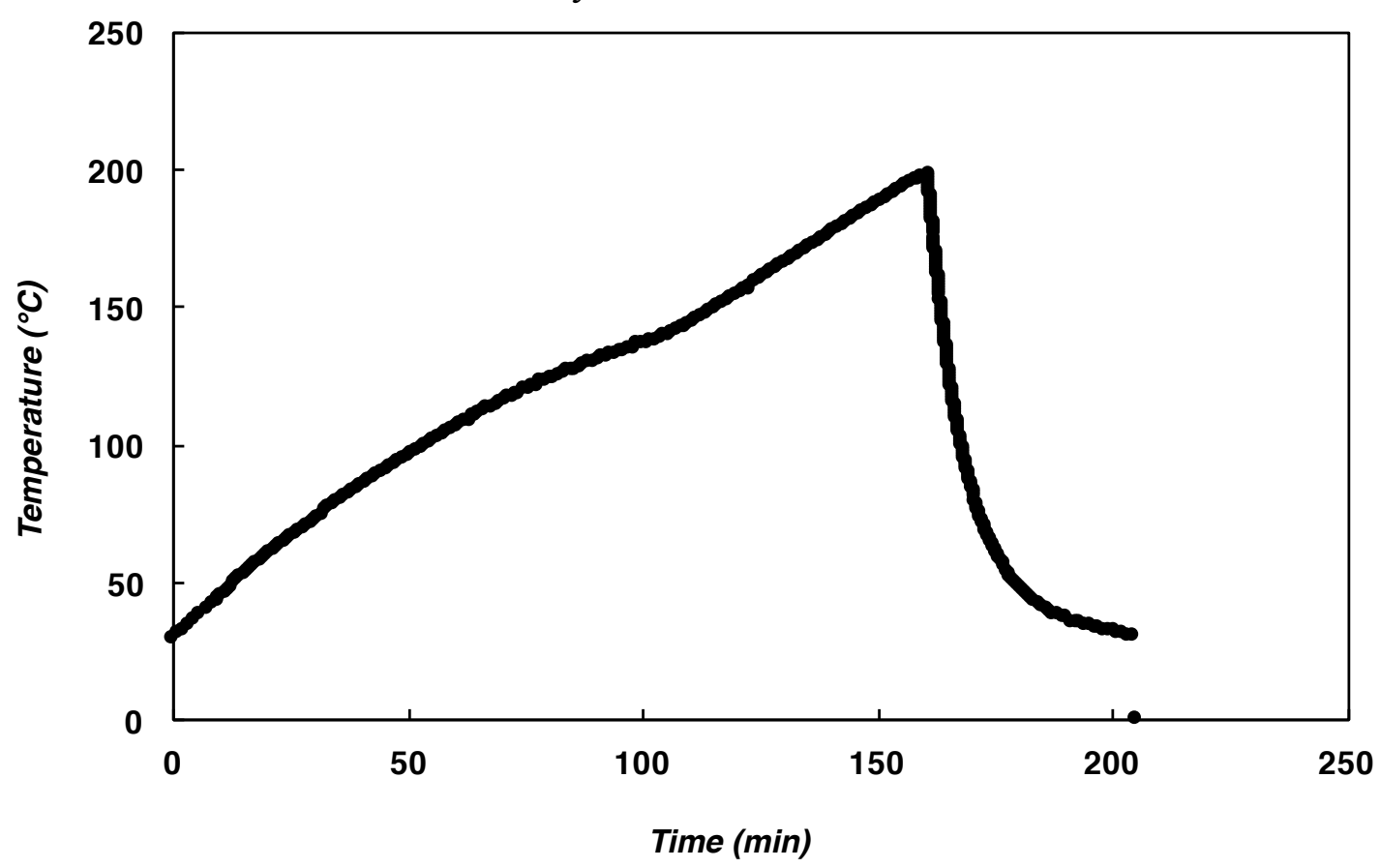

Figure S3d: Pressure vs. time plot obtained by ARSST calorimetry of Reaction Mixture A at $t=22 \mathrm{~h}$.

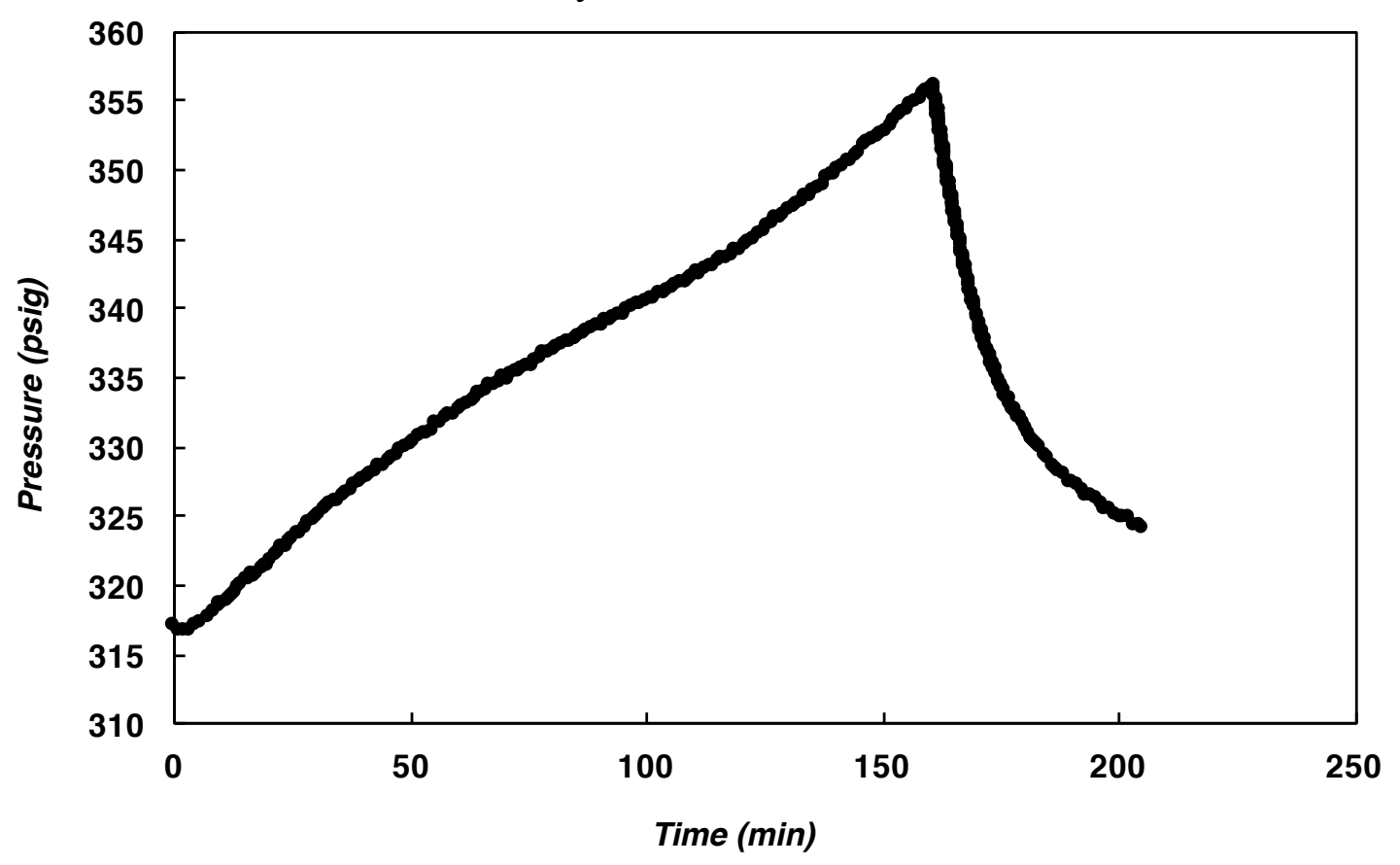


Figure S4a: Time derivative of temperature vs. time plot obtained by ARSST calorimetry without stirring of Reaction Mixture A at $\mathrm{t}=0 \mathrm{~h}$.

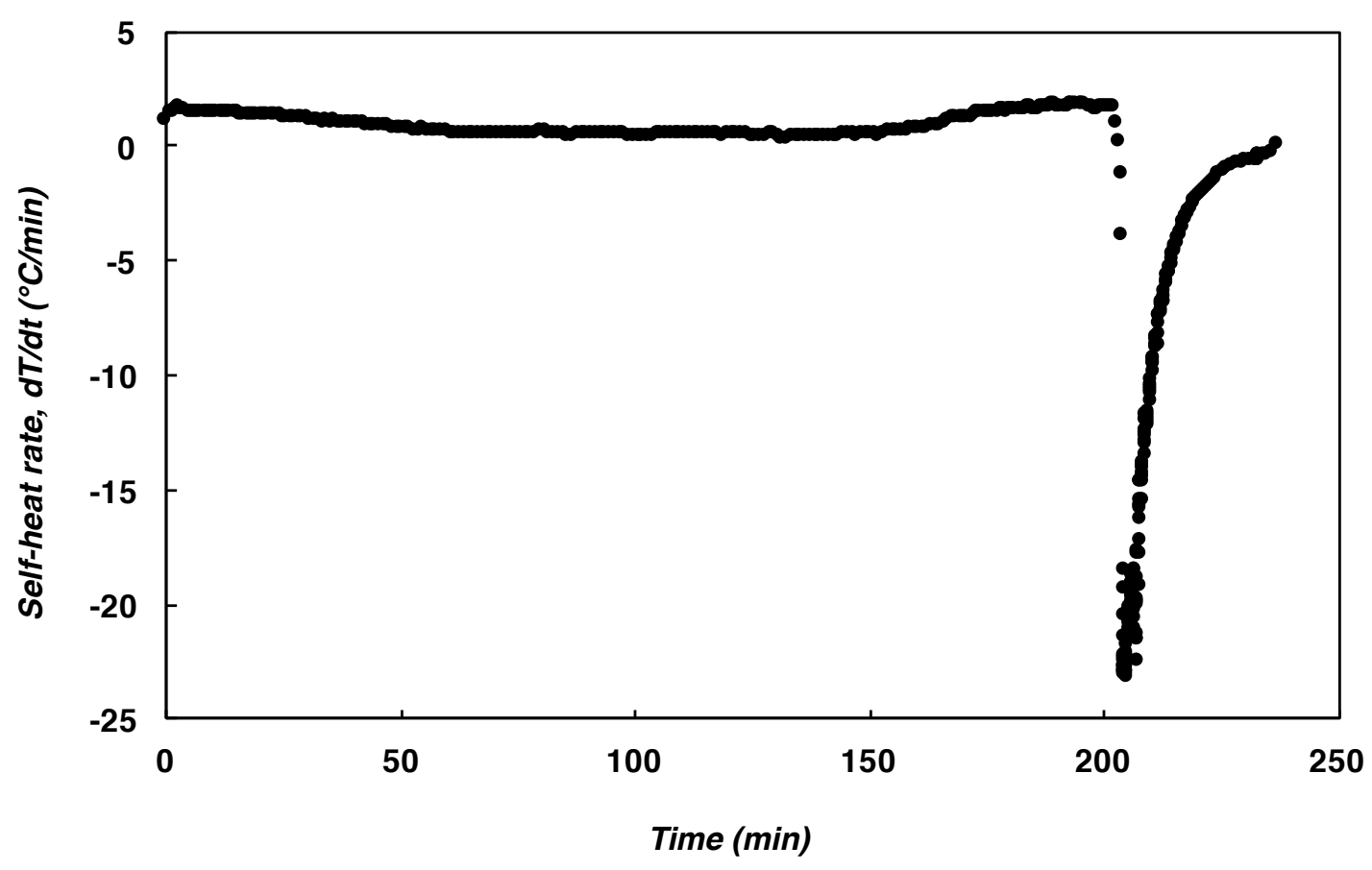

Figure S4b: Time derivative of pressure vs. time plot obtained by ARSST calorimetry without stirring of Reaction Mixture A at $t=0 \mathrm{~h}$.

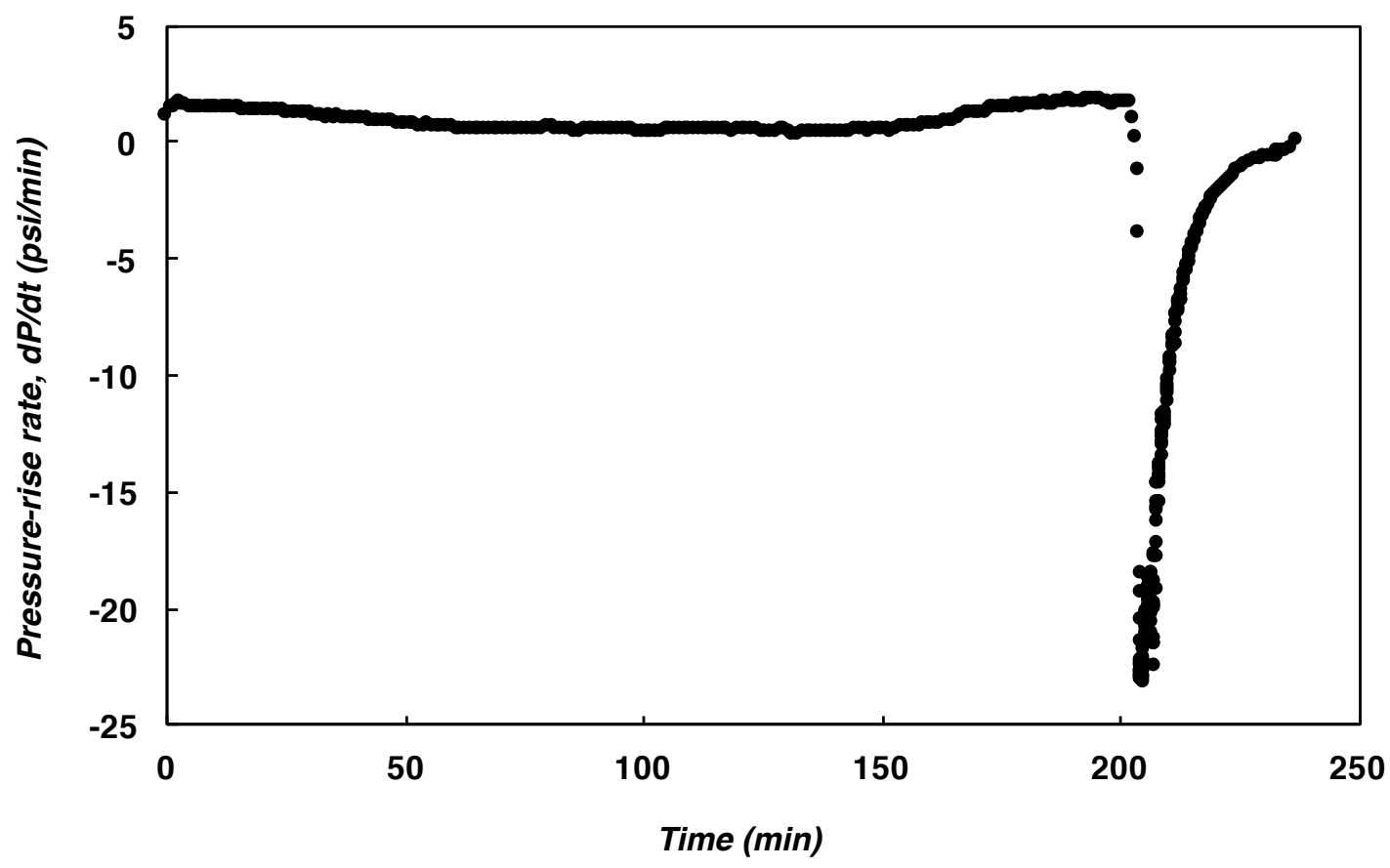


Figure S4c: Temperature vs. time plot obtained by ARSST calorimetry without stirring of Reaction Mixture A at $\mathrm{t}=0 \mathrm{~h}$.

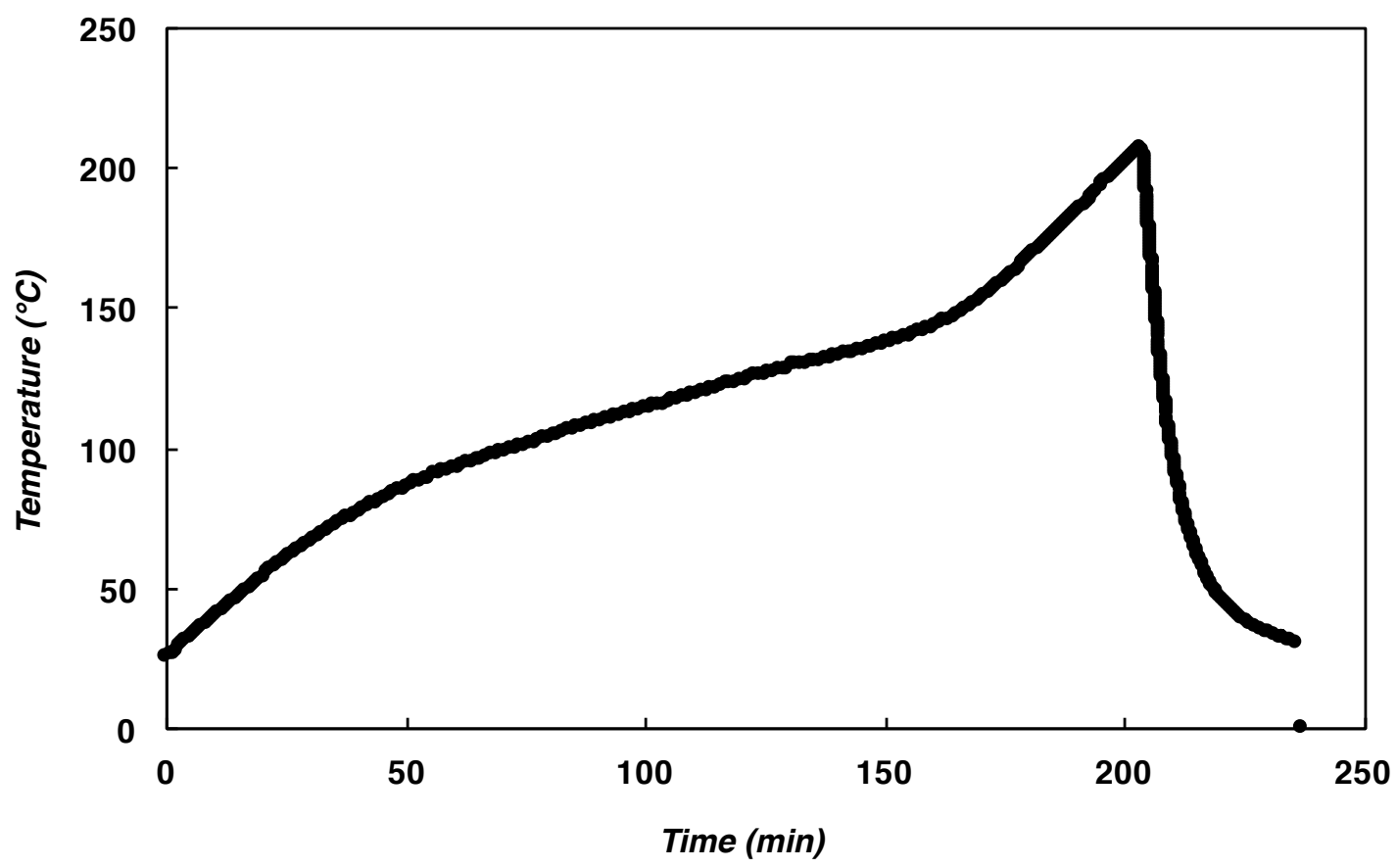

Figure S4d: Pressure vs. time plot obtained by ARSST calorimetry without stirring of Reaction Mixture A at $t=0 \mathrm{~h}$.

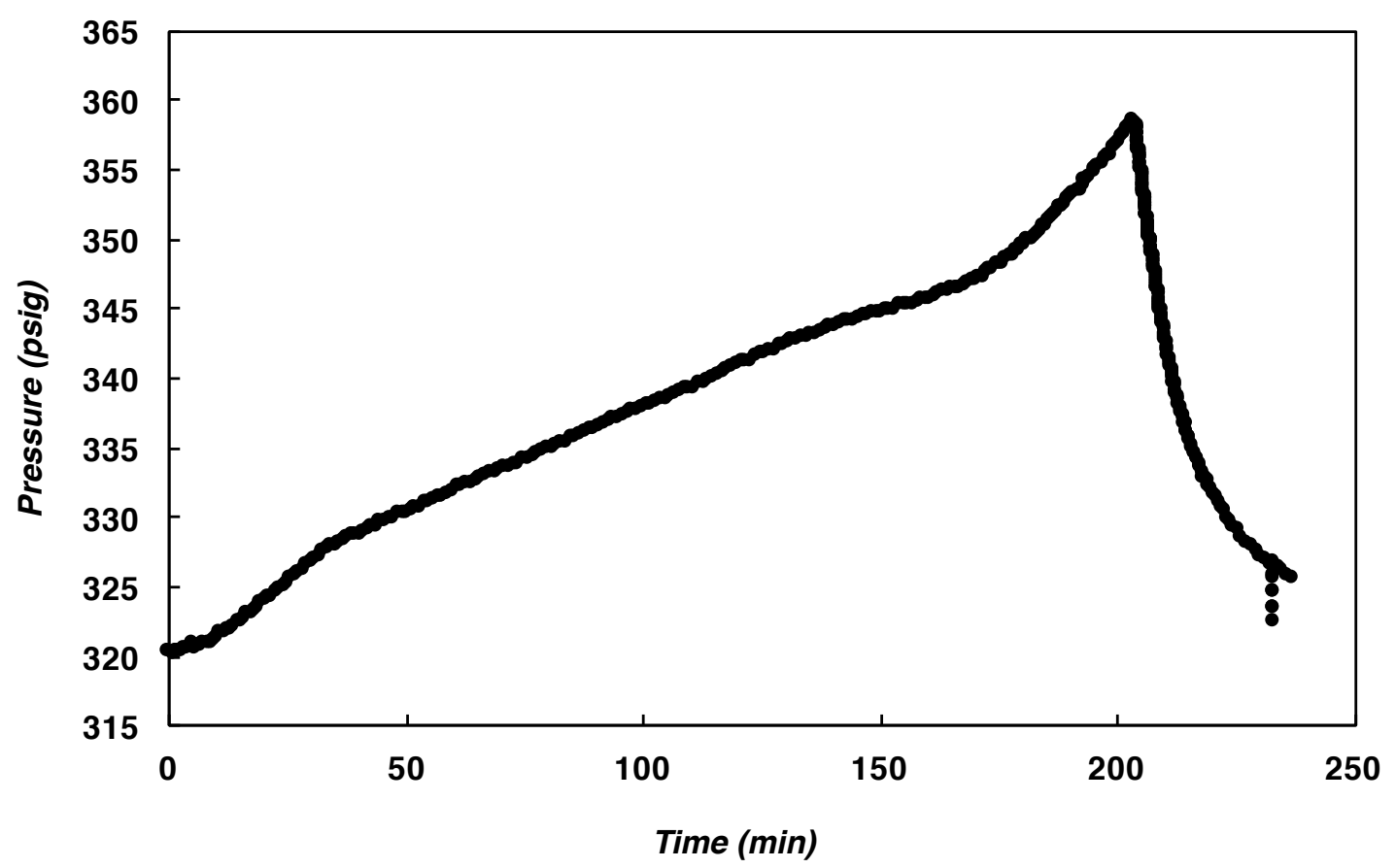


Figure S5a: Time derivative of temperature vs. time plot obtained by ARSST calorimetry without stirring of Reaction Mixture A at $\mathrm{t}=22 \mathrm{~h}$.

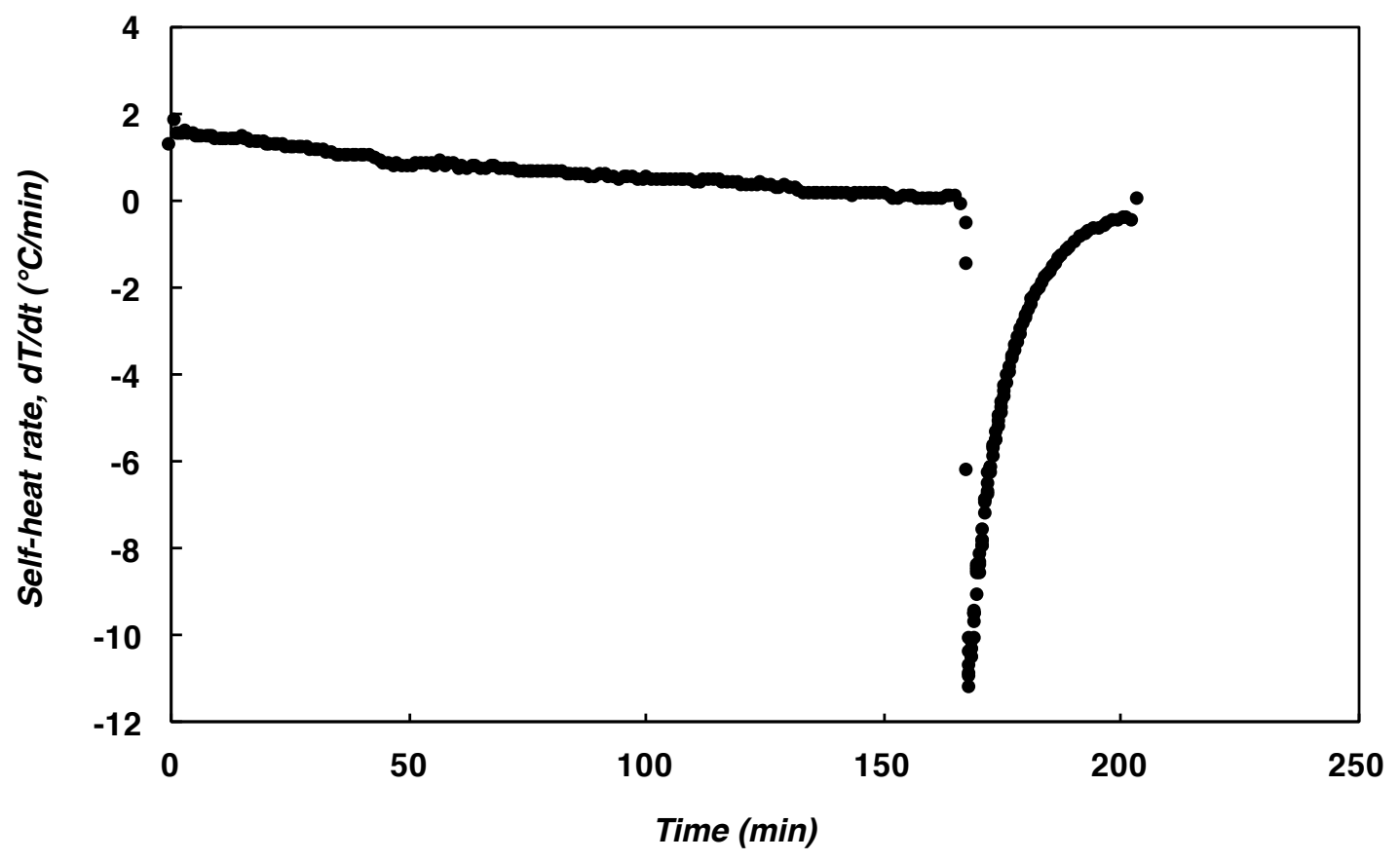

Figure S5b: Time derivative of pressure vs. time plot obtained by ARSST calorimetry without stirring of Reaction Mixture A at $\mathrm{t}=22 \mathrm{~h}$.

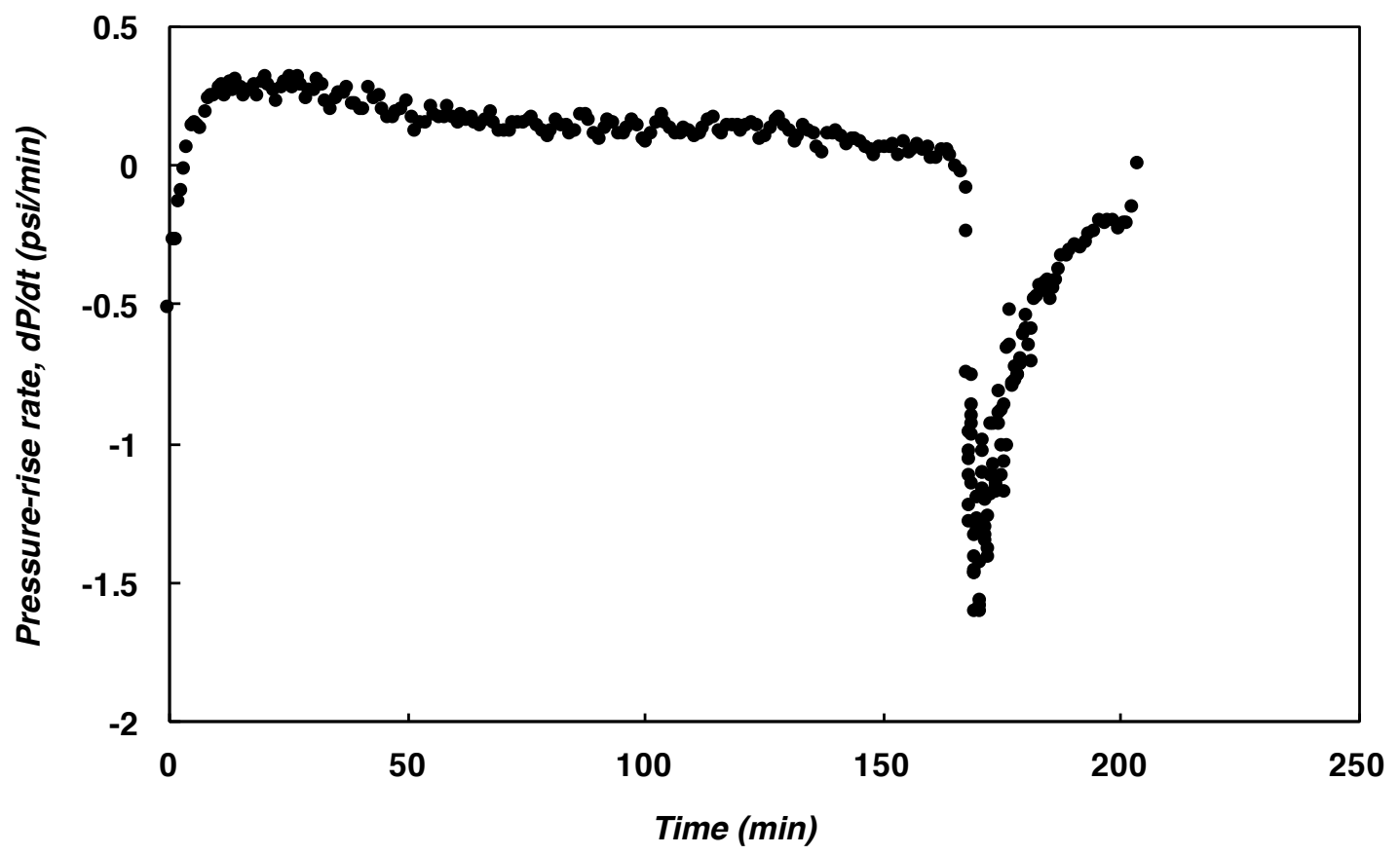


Figure S5c: Temperature vs. time plot obtained by ARSST calorimetry without stirring of Reaction Mixture A at $t=22 \mathrm{~h}$.

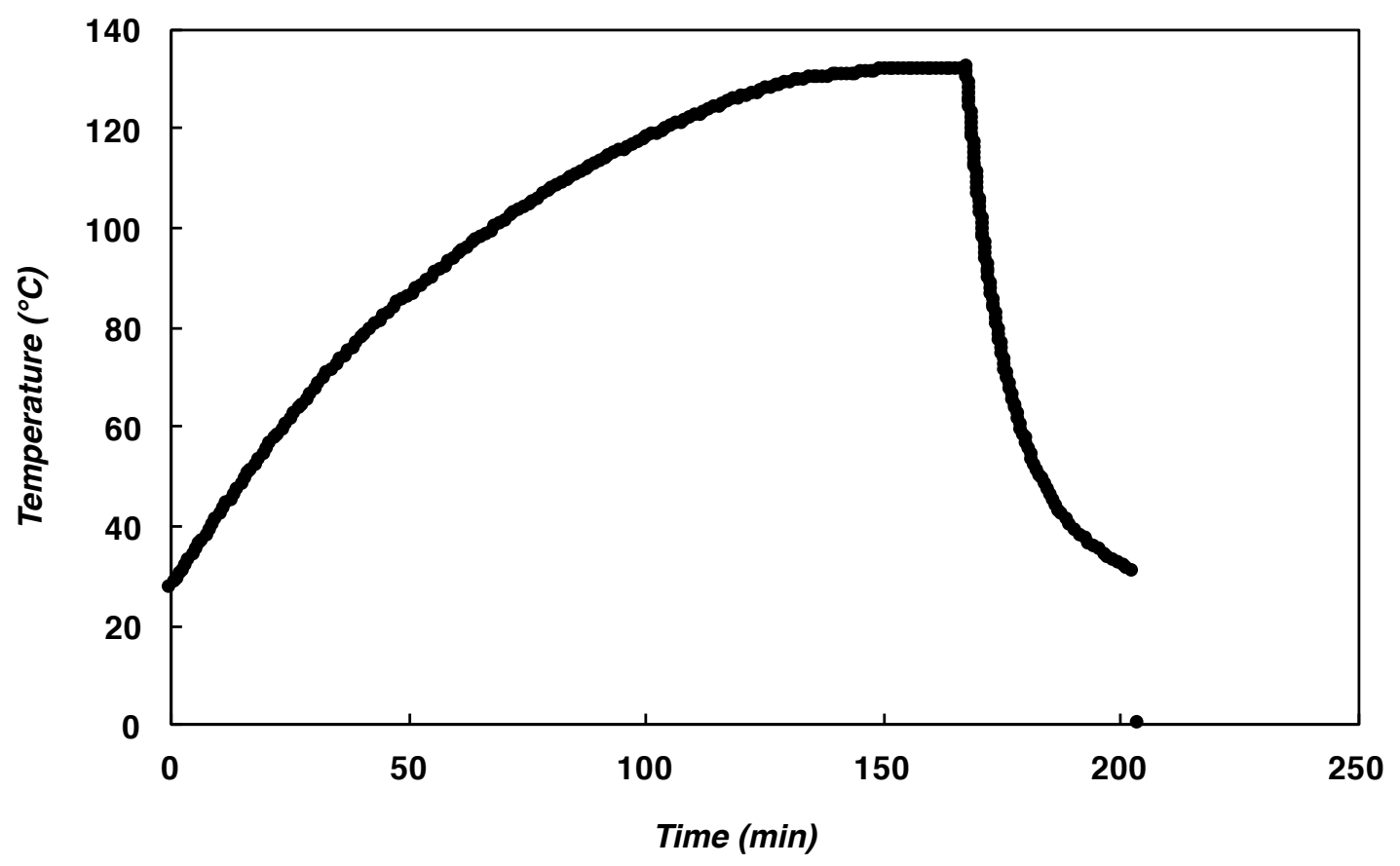

Figure S5d: Pressure vs. time plot obtained by ARSST calorimetry without stirring of Reaction Mixture A at $t=22 \mathrm{~h}$.

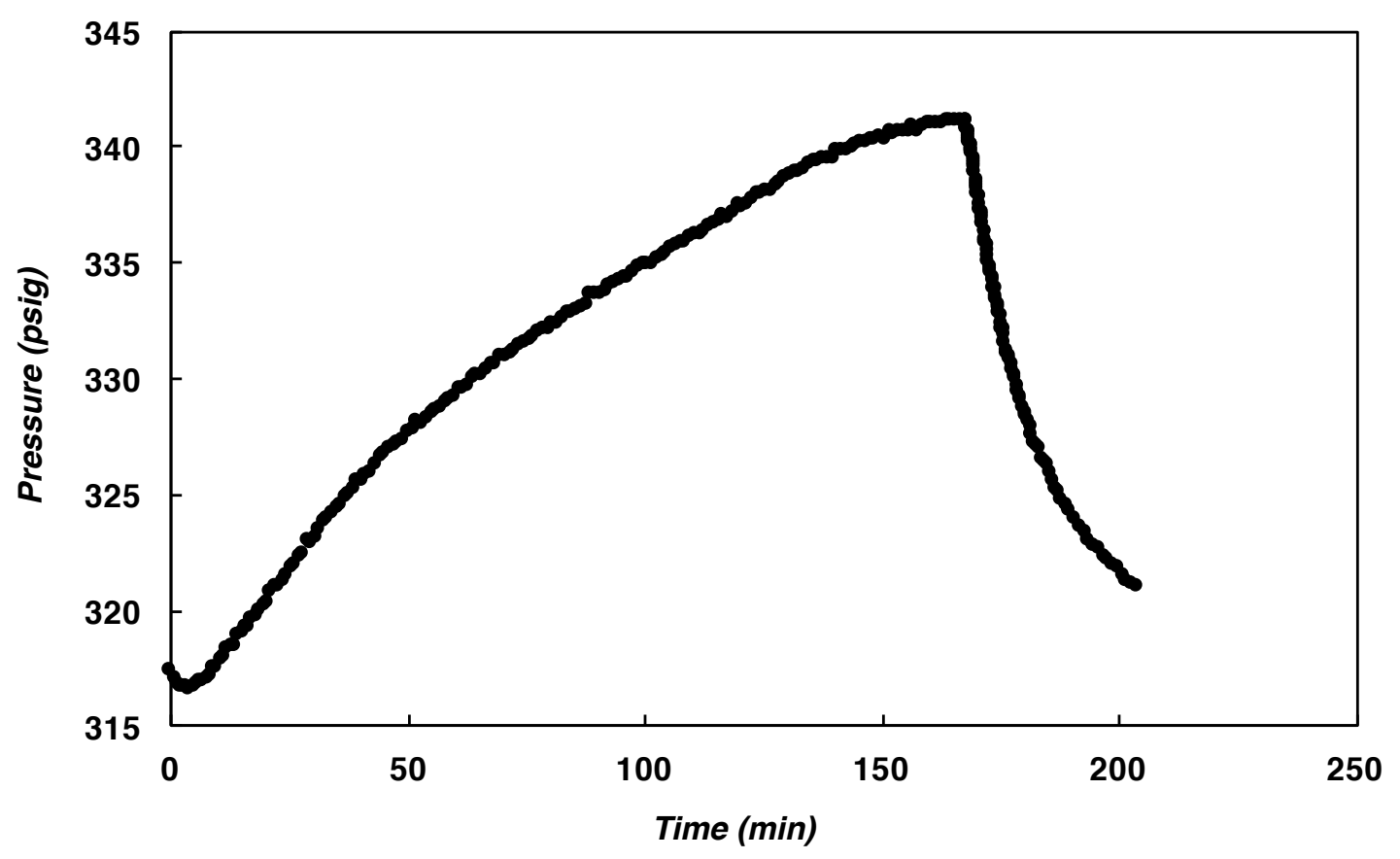


Figure S6a: Time derivative of temperature vs. time plot obtained by ARSST calorimetry of Reaction Mixture B at $\mathrm{t}=0 \mathrm{~h}$.

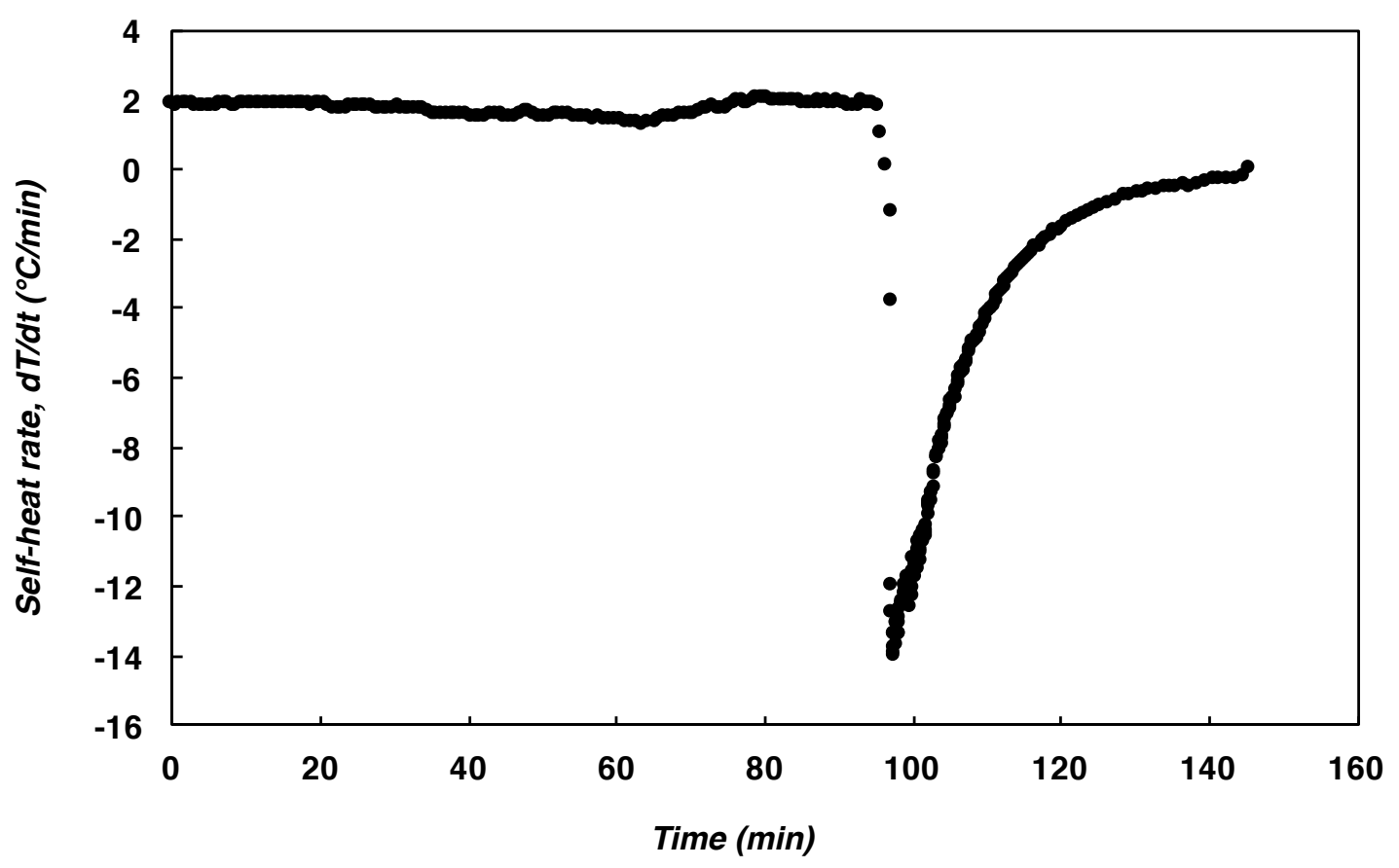

Figure S6b: Time derivative of pressure vs. time plot obtained by ARSST calorimetry of Reaction Mixture B at $\mathrm{t}=0 \mathrm{~h}$.

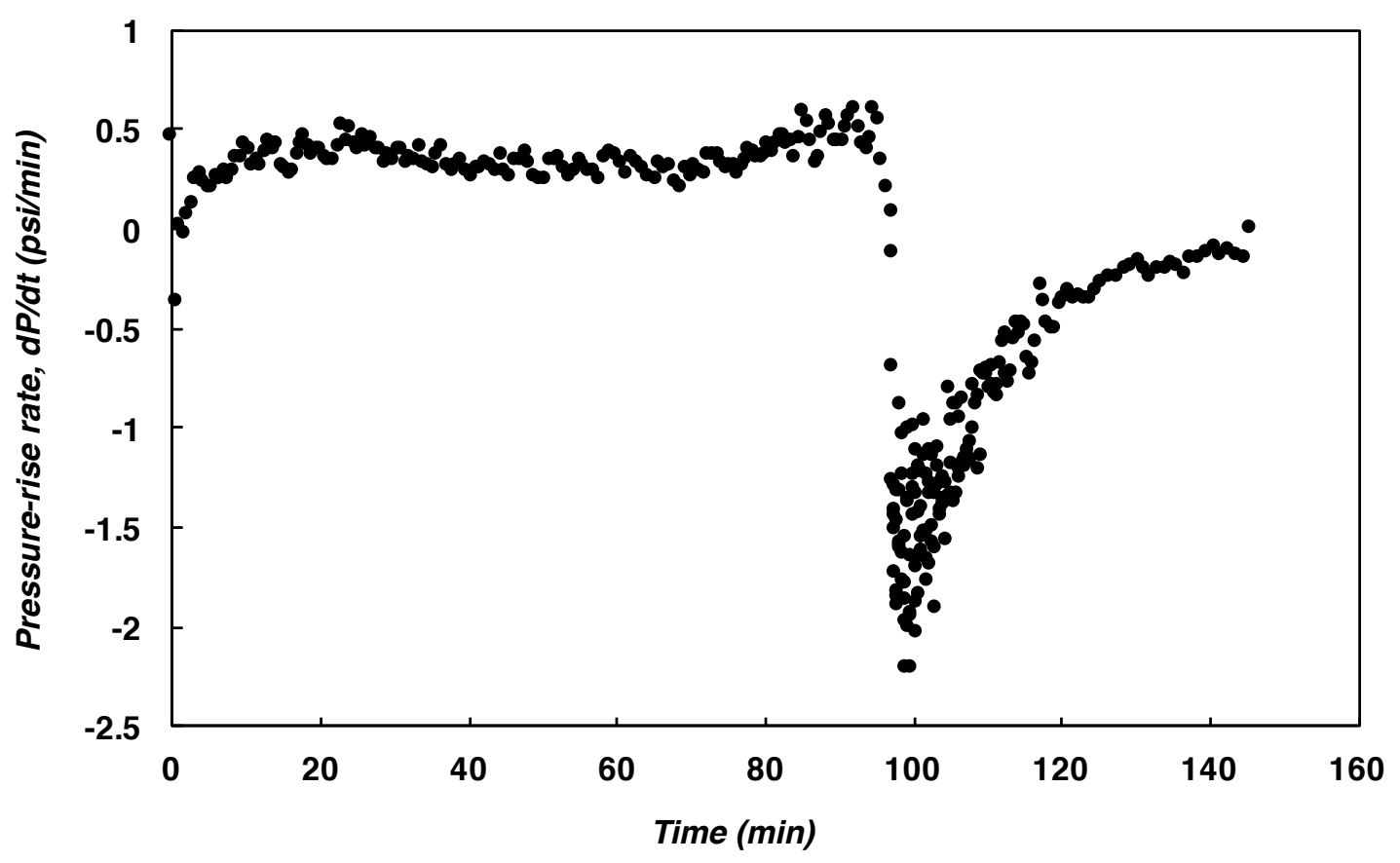


Figure S6c: Temperature vs. time plot obtained by ARSST calorimetry of Reaction Mixture B at $\mathrm{t}=0 \mathrm{~h}$.

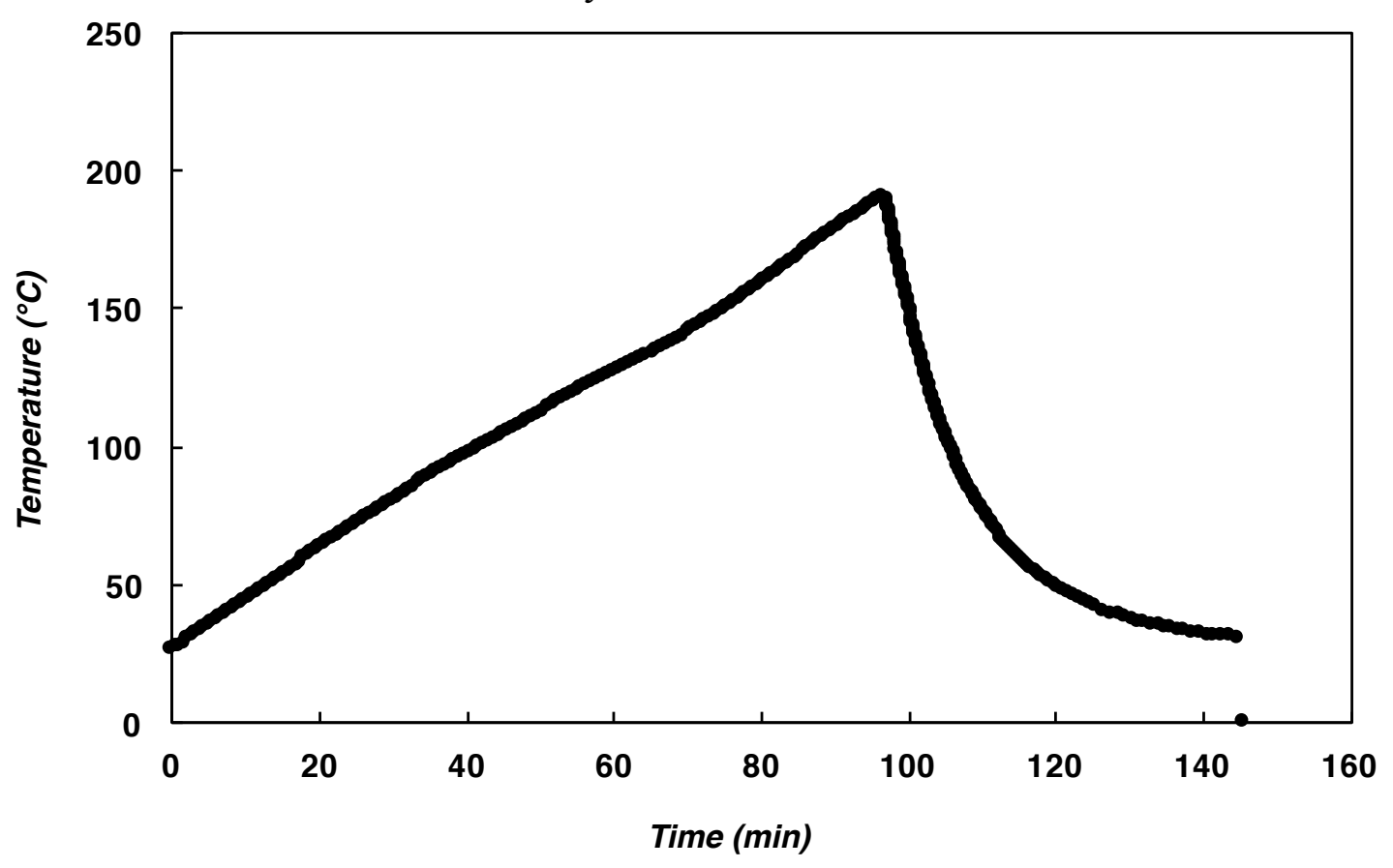

Figure S6d: Pressure vs. time plot obtained by ARSST calorimetry of Reaction Mixture B at t $=0 \mathrm{~h}$.

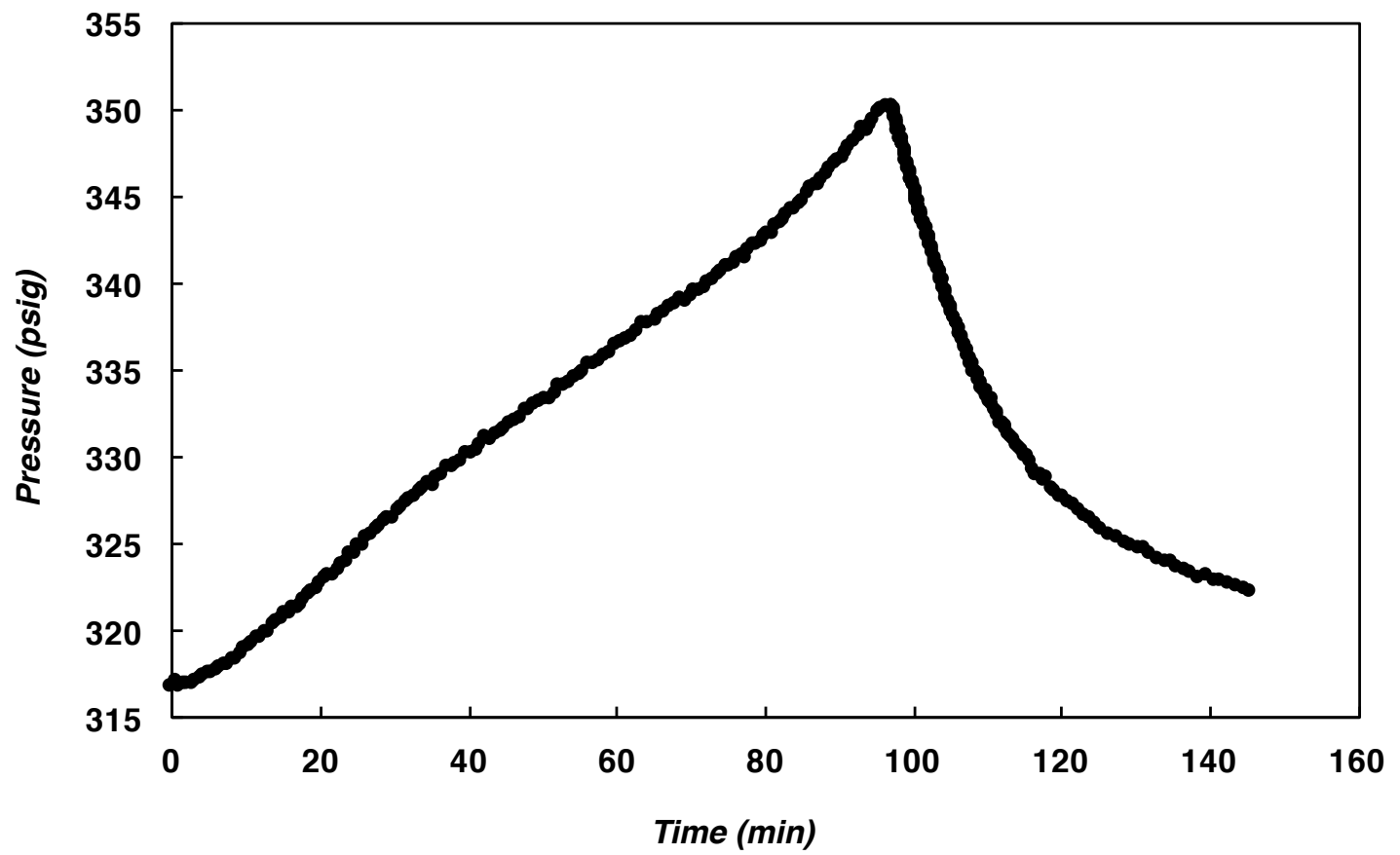


Figure S7a: Time derivative of temperature vs. time plot obtained by ARSST calorimetry of Reaction Mixture $\mathrm{C}$ at $\mathrm{t}=0 \mathrm{~h}$.

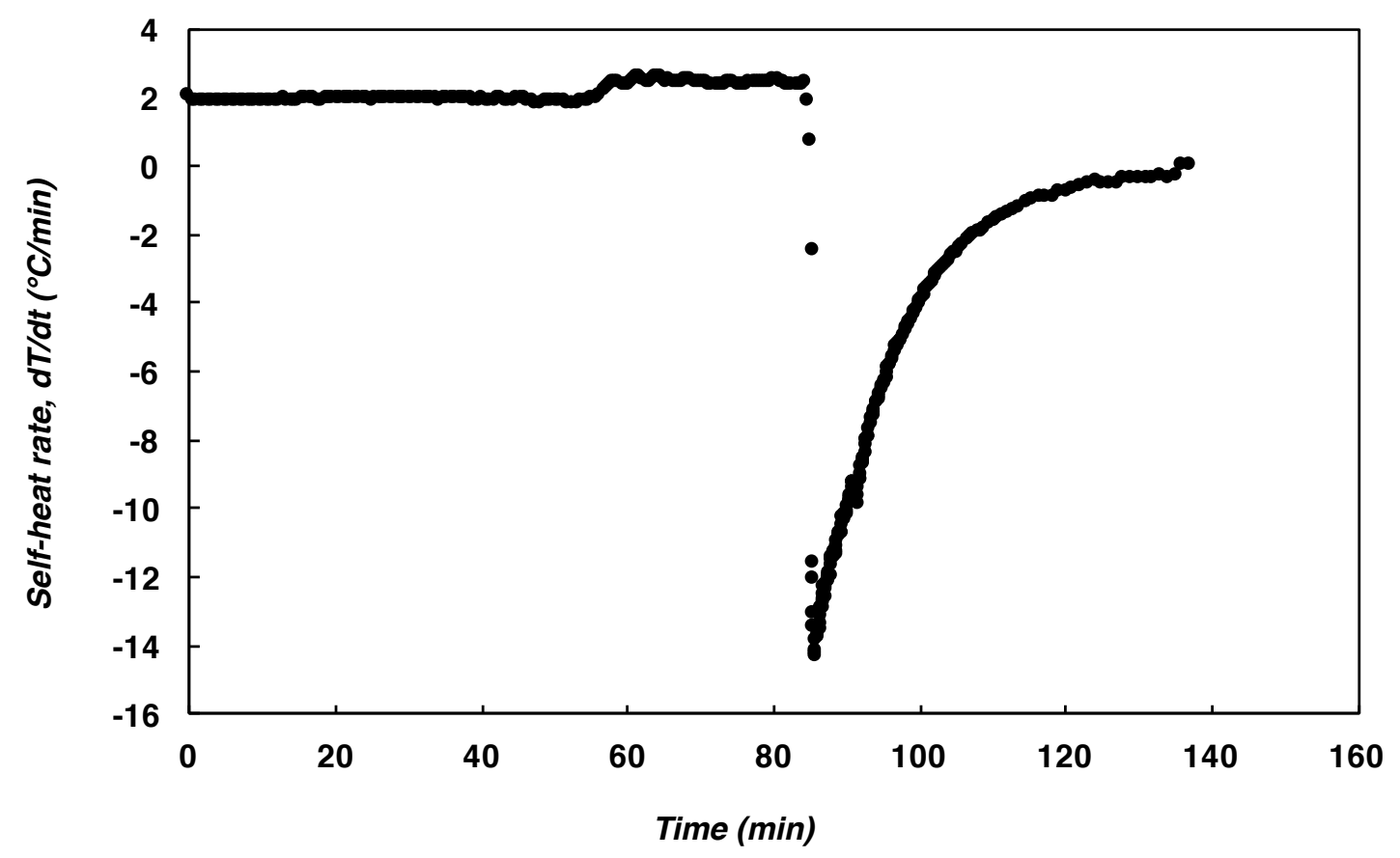

Figure S7b: Time derivative of pressure vs. time plot obtained by ARSST calorimetry of Reaction Mixture $\mathrm{C}$ at $\mathrm{t}=0 \mathrm{~h}$.

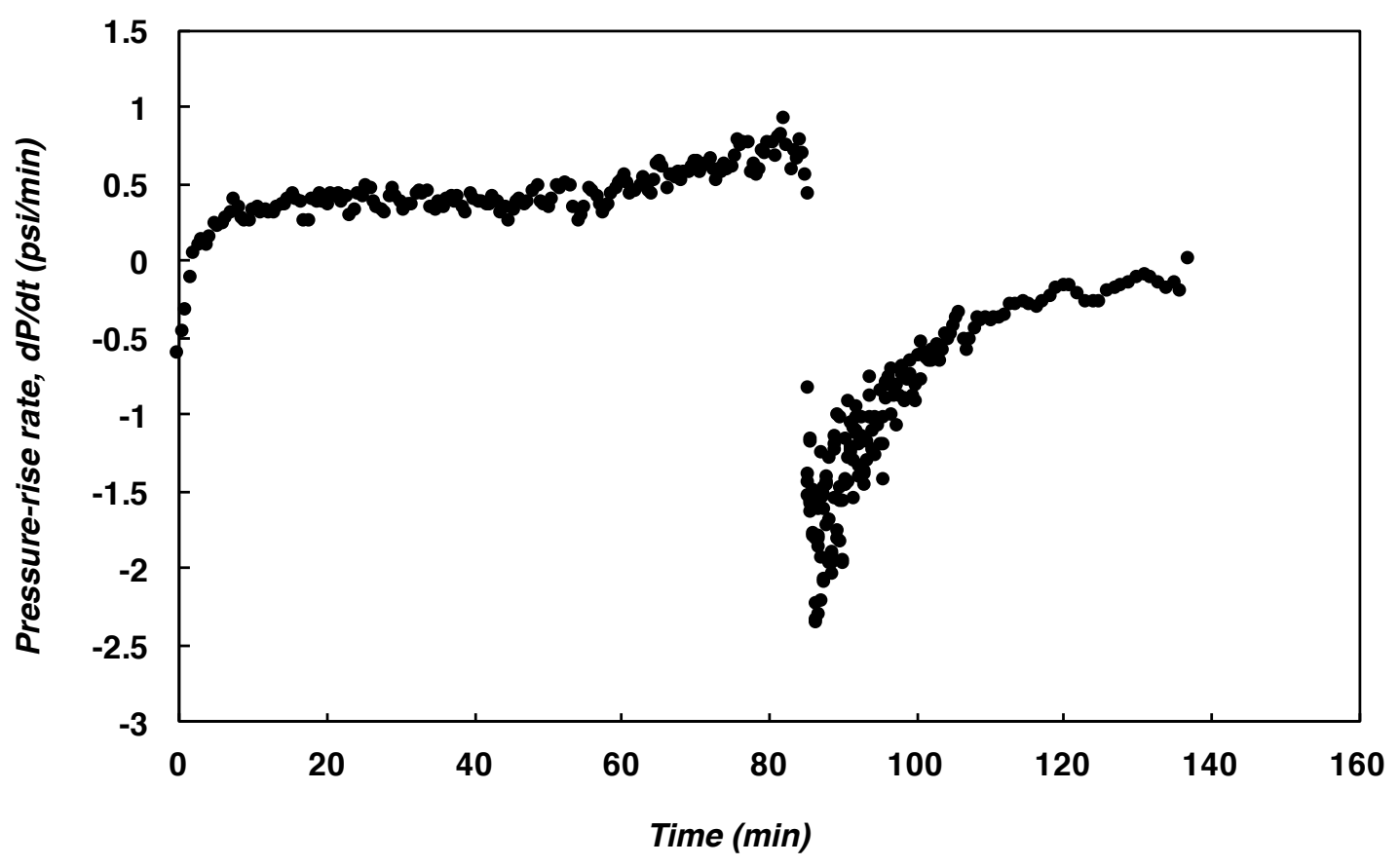


Figure S7c: Temperature vs. time plot obtained by ARSST calorimetry of Reaction Mixture $\mathrm{C}$ at $\mathrm{t}=0 \mathrm{~h}$.

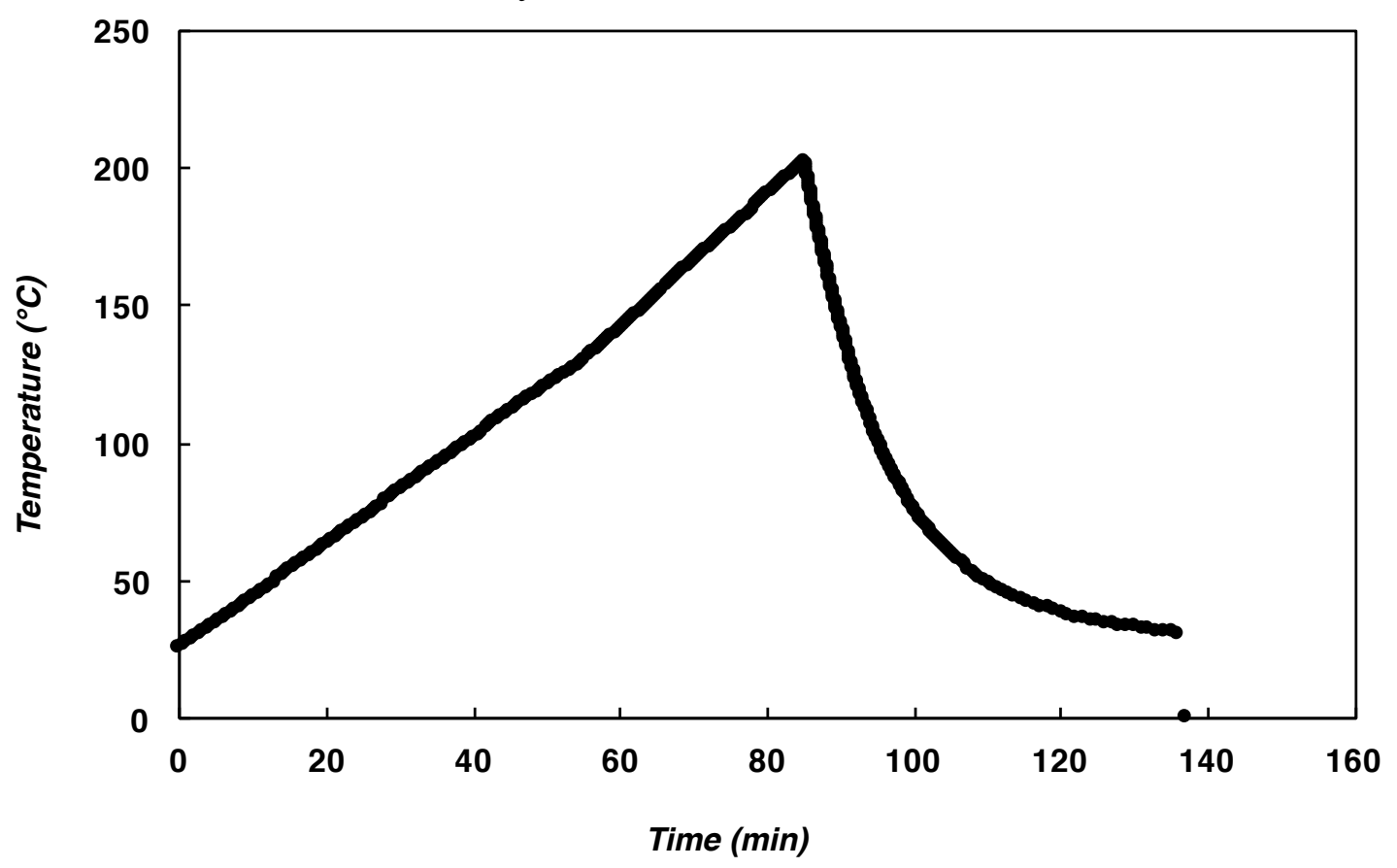

Figure S7d: Pressure vs. time plot obtained by ARSST calorimetry of Reaction Mixture C at $\mathrm{t}=0 \mathrm{~h}$.

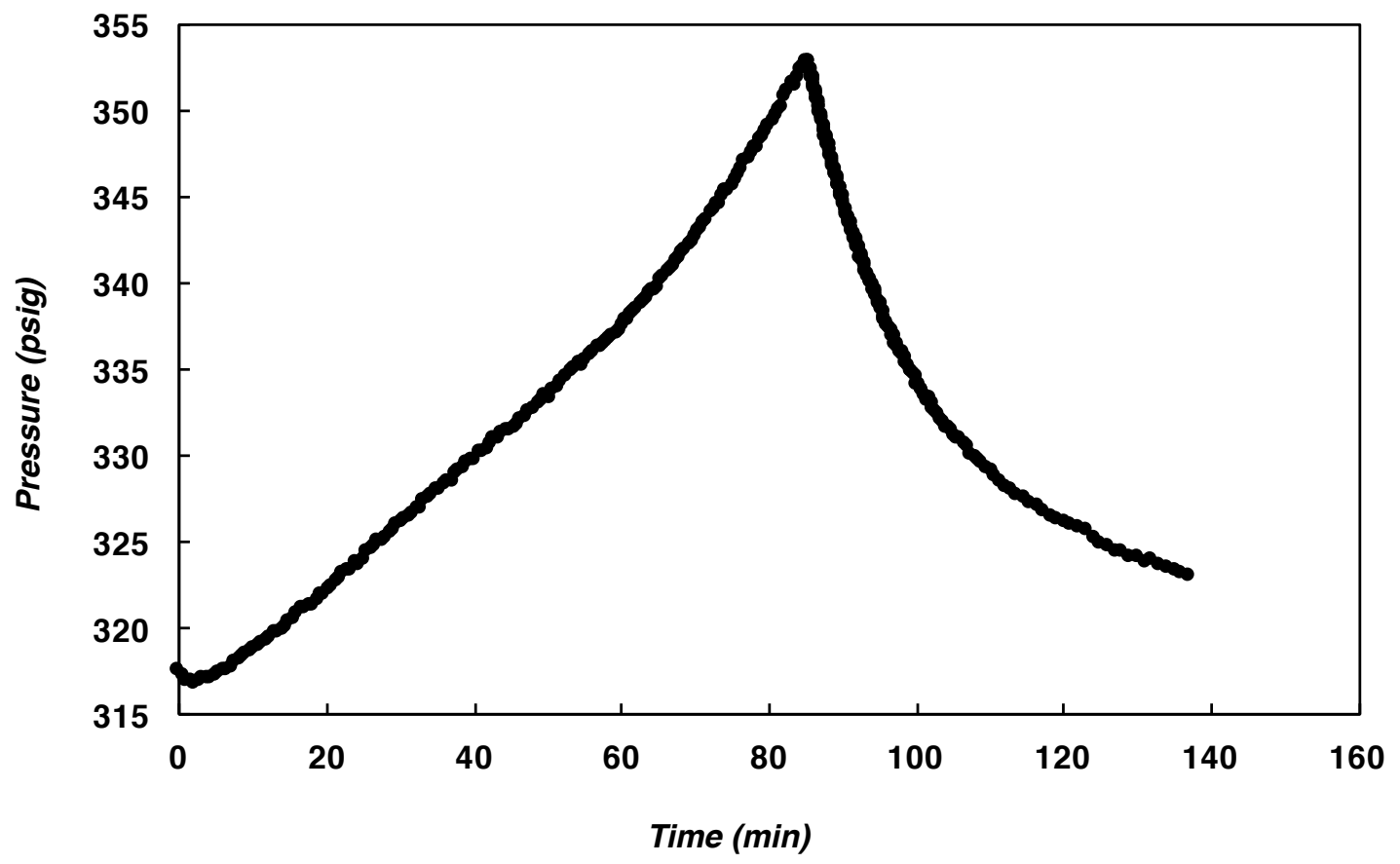




\section{B. DSC Data}

Figure S8: DSC thermogram obtained from analysis of crude oxabicycle 7.

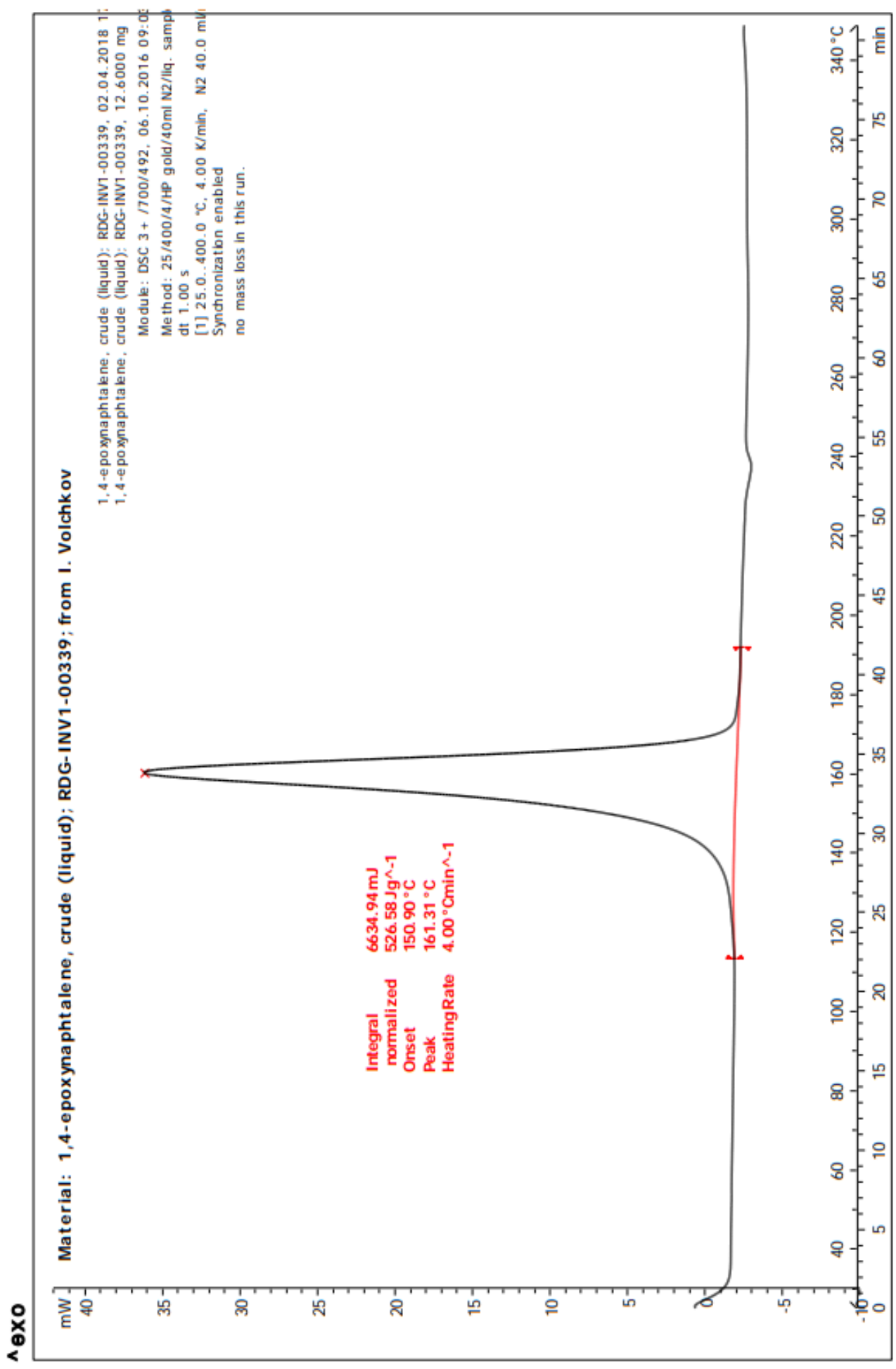


Figure S9: DSC thermogram obtained from analysis of pure oxabicycle 7.

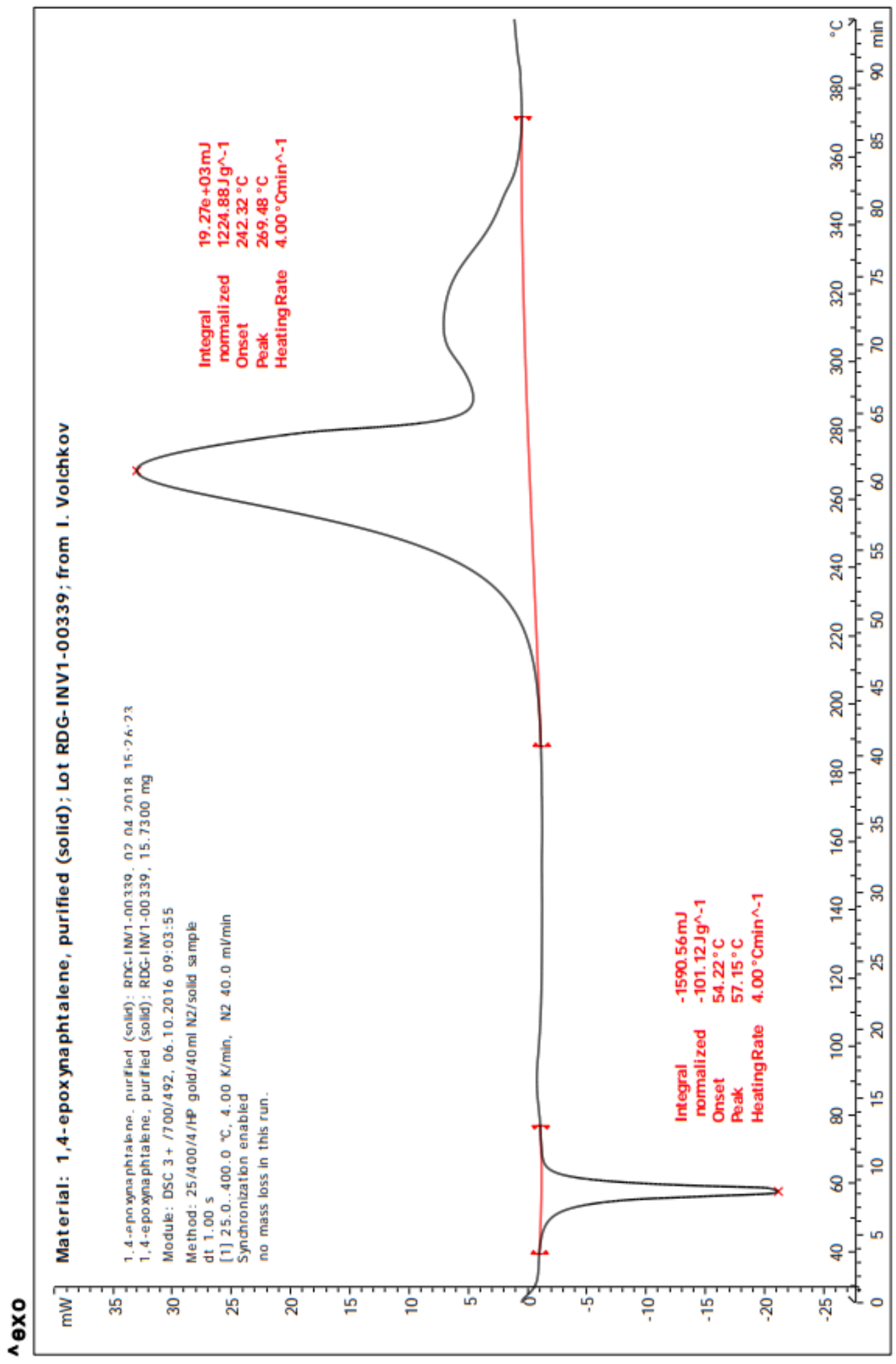




\section{Yoshida Correlation Calculations}

Eq S1: Yoshida correlation calculation for shock sensitivity potential.

Shock sensitivity $(\mathrm{SS})=\log \left(Q_{\mathrm{DSC}}\right)-0.72\left[\log \left(T_{\mathrm{DSC}}-25\right)\right]-0.98$

Where $Q_{\mathrm{DSC}}=$ Normalized heat of exotherm $[\mathrm{cal} / \mathrm{g}]$

$T_{\mathrm{DSC}}=$ Onset temperature for exotherm $\left[{ }^{\circ} \mathrm{C}\right]$

If $\mathbf{S S}>\mathbf{0}$, the compound has potential for shock sensitivity.

Crude sample SS $=\log (526.58[\mathrm{~J} / \mathrm{g}] * 1 / 4.184[\mathrm{cal} / \mathrm{J}])-0.72[\log (150.90-25)]-0.98$ $=-\mathbf{0 . 3 9}$

Purified sample SS $=\log (1224.88[\mathrm{~J} / \mathrm{g}] * 1 / 4.184[\mathrm{cal} / \mathrm{J}])-0.72[\log (242.32-25)]-0.98$ $=-\mathbf{0 . 2 0}$

Eq S2: Yoshida correlation calculation for explosion potential.

Explosion potential $(\mathrm{EP})=\log \left(Q_{\mathrm{DSC}}\right)-0.38\left[\log \left(T_{\mathrm{DSC}}-25\right)\right]-1.67$

Where $Q_{\mathrm{DSC}}=$ Normalized heat of exotherm $[\mathrm{cal} / \mathrm{g}]$

$T_{\mathrm{DSC}}=$ Onset temperature for exotherm $\left[{ }^{\circ} \mathrm{C}\right]$

If $\mathbf{E P}>\mathbf{0}$, the compound has potential for explosivity.

Crude sample $\mathrm{EP}=\log (526.58[\mathrm{~J} / \mathrm{g}] * 1 / 4.184[\mathrm{cal} / J])-0.38[\log (150.90-25)]-1.67$ $=-\mathbf{0 . 3 7}$

Purified sample EP $=\log (1224.88[\mathrm{~J} / \mathrm{g}] * 1 / 4.184[\mathrm{cal} / \mathrm{JJ}])-0.38[\log (242.32-25)]-1.67$ $=-\mathbf{0 . 0 9}$ 


\section{D. ${ }^{1}$ H NMR Spectrum}
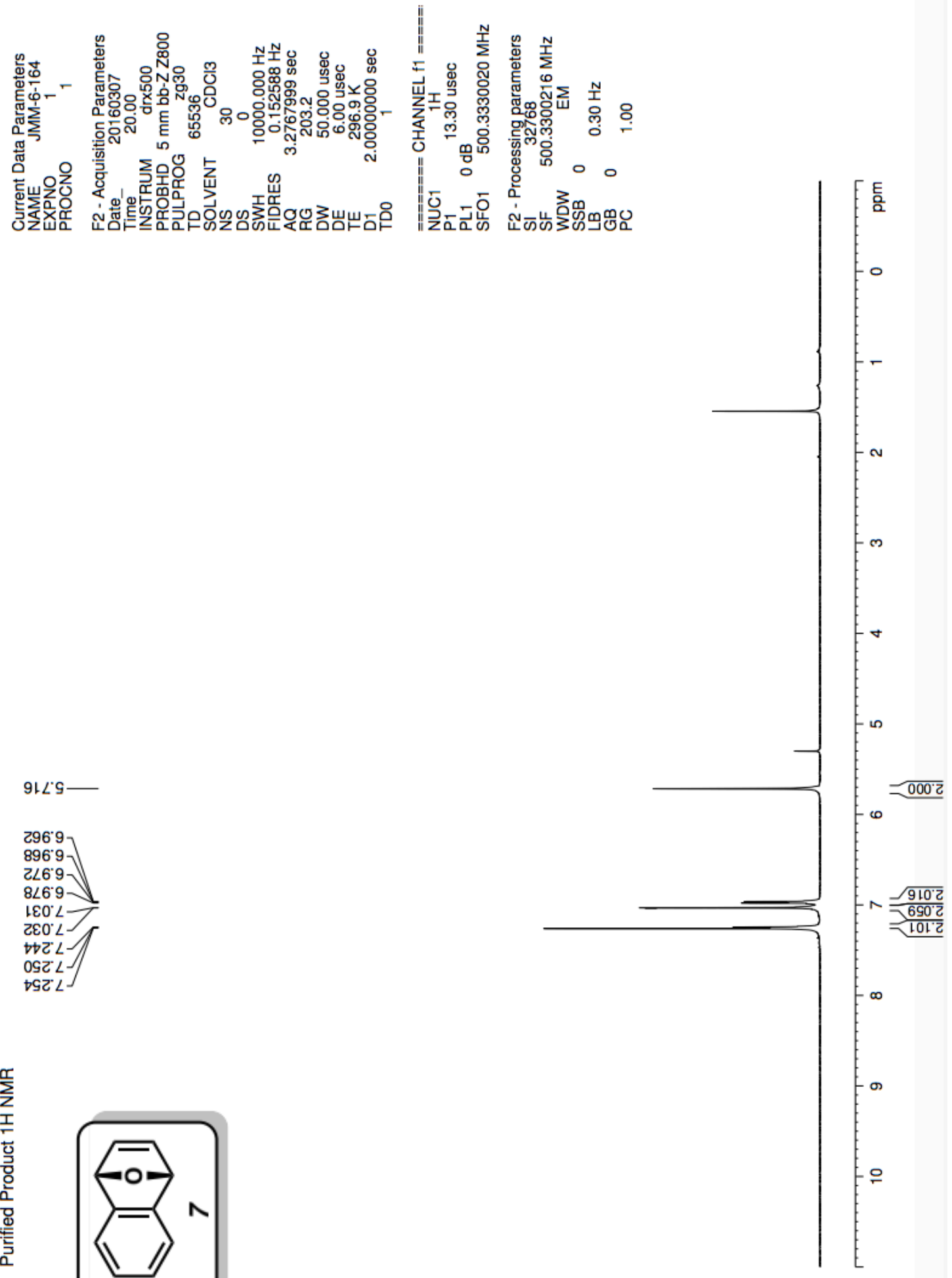


\section{References}

(1) Luo, R.; Liao, J.; Xie, L.; Tang, W.; Chan, A. S. C. Asymmetric Ring-Opening of Oxabenzonorbornadiene with Amines Promoted by a Chiral Iridium-Monophosphine Catalyst. Chem. Commun. 2013, 49, 9959-9961. 